\title{
Breathing Scarf: Using a First-Person Research Method to Design a Wearable for Emotional Regulation
}

\author{
Karen Anne Cochrane \\ Carleton Univeristy \\ Ottawa, Canada \\ karen.cochrane@carleton.ca \\ Audrey Girouard \\ Carleton Univeristy \\ Ottawa, Canada \\ audrey.girouard@carleton.ca
}

\author{
Yidan Cao \\ School of Architecture, Design and Planning, The \\ University of Sydney \\ Sydney, Australia \\ Lian Loke \\ Affective Interactions Lab, School of Architecture, Design \\ and Planning, The University of Sydney \\ Sydney, Australia
}

\begin{abstract}
The cognitive complexities of emotions and individualized coping strategies make it a difficult space for design. Collecting first-person data can provide nuanced understanding of the lived experience of emotional life, to better inform the design of wearable technologies for emotional self-regulation. We present a preliminary study of our first-person phenomenological approach to autobiographical design. The methodology is unique for the intertwining of emotional activities and mindfulness exercises, as a strategy for controlling emotional repercussions. Self-observation and documentation included journaling and sketching using the Inside-Out Probe workbook, followed by material prototyping and testing in-the-wild. The Breathing Scarf prototype embodies the design considerations. In designing for one to support personalized self-regulation strategies, key considerations include designing for personal comfort, ownership, and individual-over-social meaning-making. Of equal importance in the design research process are the well-being of the designer/researcher, the ability to self-regulate emotions, and the ethics of care and emotion work.
\end{abstract}

\section{CCS CONCEPTS}

- Human-centered computing $\rightarrow$ HCI design and evaluation methods; Field studies.

\section{KEYWORDS}

First-person research; autoethnography; autobiographical design; design research; wearable technology; emotional regulation

\section{ACM Reference Format:}

Karen Anne Cochrane, Yidan Cao, Audrey Girouard, and Lian Loke. 2022. Breathing Scarf: Using a First-Person Research Method to Design a Wearable for Emotional Regulation. In Sixteenth International Conference on Tangible, Embedded, and Embodied Interaction (TEI '22), February 13-16, 2022, Daejeon, Republic of Korea. ACM, New York, NY, USA, 19 pages. https://doi.org/10. $1145 / 3490149.3501330$

\section{(c) (†) $\ominus$}

This work is licensed under a Creative Commons

Attribution-NonCommercial-NoDerivs International 4.0 License.

TEI '22, February 13-16, 2022, Daejeon, Republic of Korea

(c) 2022 Copyright held by the owner/author(s).

ACM ISBN 978-1-4503-9147-4/22/02.

https://doi.org/10.1145/3490149.3501330

\section{INTRODUCTION}

In recent years, mental health and emotional well-being have become important topics on national healthcare agendas. Along with psychological therapy approaches [5], we have witnessed a corresponding rise in mindfulness meditation $[54,55]$ as a practical and accessible tool open to anyone who wishes to gain agency in their own mental health care, as well as learning to self-regulate their emotions. Emotional regulation is the ability to effectively manage and respond to an emotional experience [88]. Emotional disregulation can lead to severe psychological distress, which can, in turn, lead to mental health disorders and addictions [1, 10, 46, 100]. There are many positive coping strategies to help strengthen emotional regulation [43, 66]; a common strategy is attention to breath (ATB). ATB is a simple exercise in mindfulness meditation where the practitioner focuses on taking slow deep breaths. Research has shown that ATB can help practitioners stabilize and regulate their emotions [24, 30, 111].

Prior research in human-computer interaction (HCI) has explored a variety of interactive technologies to assist people with emotional regulation to improve their health and well-being [16$18,33,53]$. Wearable technology in particular has employed biofeedback data to assist with emotional self-regulation [40, 41, 111]. However the cognitive complexities of emotions and individualized coping strategies make it a difficult space for design. One size does not fit all. Instead of designing for the mass market, an alternative approach with roots in craft-based jewelry design is to design for one. Crafting a bespoke design for a client is common in practices of jewellery design when working with traditional materials to produce objects of personal significance [61]. Introducing electronics and digital interactivity into the realm of jewelry opens up new opportunities for design, yet simultaneously complicates the design process and the final product [59]. This is especially so when designing to support individual preferences for emotional self-regulation. 


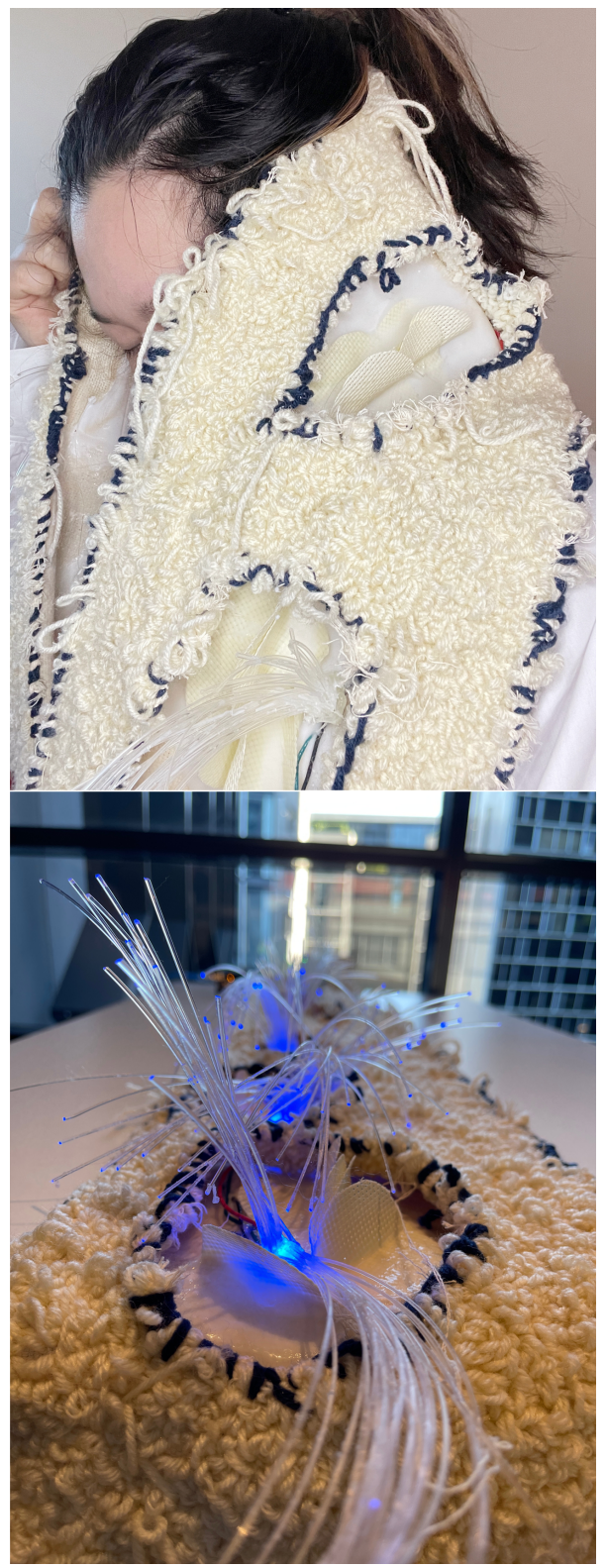

Figure 1: [Top Image] The design researcher wearing the final prototype entitled The Breathing Scarf. [Bottom Image] The prototype The Breathing Scarf lying on a table.

To better understand this design space, we turned to first-person autobiographical design research [76]. First-person research investigates the lived experience of a single participant or a group of participants which can be used to inform design [23, 48, 68, 76]. For our study, we are interested in a single user's emotional experiences to inform the design of a piece of wearable technology to support emotional self-regulation. To collect the data we developed a workbook which includes activities of writing and sketching to understand the lived experience of the design researcher. A important contribution of the methodology is the Inside-Out Probe
Workbook. It is adapted from Cochrane et al. [15] by customizing it for the design space of emotional self-regulation, and adding designerly sketching activities for reflection and ideation. Comparable to Neustaedter and Sengers, our approach uses "extensive, genuine usage by those creating or building the system" [76, p. 514].

Although many researchers in HCI collect first-person data through a group of users or researchers [15, 48, 76, 92], we are interested in exploring how to design for the self to support personalized emotion regulation practices. Our rationale in designing for the self of the design researcher first, prior to designing for a client, is to explore and test methods for eliciting individual experiences of emotional situations and potential strategies to learn and practice self-regulation of emotions assisted by wearable technology. We cast this as an ethical issue of designers using their own bodies and lived experiences to gain an empathic understanding of emotional life, and associated concerns and risks, before asking clients and users to participate in any design or research process requiring emotion work [47, 48].

The aim of the study is to explore how designing for one (or in this case the design researcher) can produce bespoke wearables that support personalized emotion regulation. The paper presents data collected from the second author of the paper where both the first and second author worked collaboratively to analyze the firstperson data and design the prototype. The second author crafted the final prototype. For the rest of the paper, we will refer to the second author as the design researcher. The design research process adopted a first-person phenomenological approach to autobiographical design, which included self-observation of emotion-triggering activities, interleaved with a mindfulness breathing exercise, journalling and sketching, crafting and prototyping, self-testing and evaluation of prototypes. The resultant prototype The Breathing Scarf (Figure 1), a hand-crafted wearable scarf with embedded electronics, incorporated the positive coping strategy of ATB into the interaction design through personalized choices regarding display of biodata. The scarf collected galvanic skin response data through DIY sensors, which triggered the fading LEDs as a guide for the ATB exercise. Detail about the use of sensor list can be seen in Table 1.

In the paper, we review the literature on emotional regulation with particular attention to mindfulness-based breathing, emotional regulation technology in HCI, the fusion of wearable technology and jewelry, and finally, first-person research in HCI. Then we describe our study design, followed by the results of the selfexperimentation and observation activities, the design ideation, material exploration and prototyping activities, and the self-testing and evaluation activities. The discussion explores a set of design considerations related to desired qualities of the product, as well as the design process. In designing for one to support personalized self-regulation strategies, key considerations include designing for personal comfort, ownership, and individual-over-social meaningmaking. We also reflect upon key concerns in the design research process of the well-being of the designer/researcher and the ability to self-regulate emotions, as well as the ethics of care and emotion work. We conclude with our contributions of a design research case study, the Inside-Out Probe workbook, a design research methodology suited to exploring emotional experiences and self-regulation strategies, and a hand-crafted wearable prototype The Breathing 
Scarf that embodies the design considerations. We outline directions for future research, including the challenge of how to translate designing for one from the design researcher's lived emotional experience to co-designing with a client who wishes to incorporate an emotional self-regulation practice into a bespoke wearable.

\begin{tabular}{|l|c|c|c|c|}
\hline $\begin{array}{l}\text { Prototype/ } \\
\text { Electronic } \\
\text { components }\end{array}$ & Main board & GSR sensor & LED Light & Force sensor \\
\hline $\begin{array}{l}\text { Prototype } \\
\text { Version 1 }\end{array}$ & Lily pad & Yes & & \\
\hline $\begin{array}{l}\text { Prototype } \\
\text { Version 2 }\end{array}$ & Arduino Uno & Yes & Yes & \\
\hline $\begin{array}{l}\text { Prototype } \\
\text { Version 3 }\end{array}$ & Arduino Uno & Yes & Yes & Yes \\
\hline
\end{tabular}

Table 1: Table summarising the different versions of the prototypes in terms of electronic components.

\section{RELATED WORK}

\subsection{Emotional Regulation}

According to Gross, emotional regulation is defined as "the processes by which individuals influence which emotions they have, when they have them, and how they experience and express these emotions" [33, p. 1]. It has a pivotal role in our health and wellbeing. A large and growing body of literature concludes that our physical and psychological well-being is affected by our emotional state and that the body, mind, and emotions are interconnected $[3,22,36,60,81,108]$. There are different types of emotional regulations strategies that vary from person to person [110]. Two of the more popular methods for emotional regulation include cognitive reappraisal and expressive suppression. People use these two strategies to daily manage their emotions and to cope with everyday activities [88].

Cognitive reappraisal is considered a positive coping strategy and is an attempt to reframe an emotional circumstance to a different meaning and emotional impact [34, 62]. It refers to the reorganization of emotion and re-evaluates the lived experience to change the way a person thinks. Expression suppression refers to hiding, suppressing, or reducing emotional lived experiences; it is a process of pressing down strong emotions [33, 35]. For example, if you are late to a meeting, you could rethink the situation instead of getting frustrated in yourself, by saying to yourself "life happens" (cognitive reappraisal), or suppress the frustration with a smile but on the inside remaining quite frustrated with yourself (expressive suppression). Researchers have concluded that reappraisal is healthier than suppression, implying that suppression can negatively affect your health and well-being [39, 51]. Neural-based studies also indicated that reappraisal and suppression are effective for emotional regulation but have different efficacy, and reappraisal works faster than suppression [31, 57]. Other strategies such as avoidance (avoiding the situations) [9], capitalizing (expanding the positive emotions) [62], and problem-focused coping (finding a way to deal with stressful situations) [63], have different effects on different emotions. Another strategy for emotional self-regulation is interoceptive awareness (IA). IA involves recognizing one's physiological state and understanding internal sensations [28, 72,84$]$. It has the potential to help people regulate their negative emotions, which will help improve their emotional regulation [26, 67, 74, 82]. It requires a person to be self-aware [19]. There are opportunities in wearable technology to collect biofeedback to increase a person's IA.

In addition to the diversity of emotion regulation strategies and the efficacy of strategies, emotional regulation varies across individual people, for example, through personality and cultural differences [6, 39, 71, 78, 85, 86]. Everyone's lifestyle, living environment, culture, and personality are different, resulting in considerable variation in emotional regulation strategy preferences. These discrepancies make it difficult for designers to select appropriate emotional regulation strategies during the design process. As a result, when humans and their emotions become the protagonists of the design, we must consider the uniqueness of everyone's emotions. The improper use of emotion regulation strategies may harm users' physical and psychological well-being [110].

It can be difficult to get into the right mindset during an intense emotional experience, where a person can initiate cognitive reappraisal. The breathing exercise in mindfulness meditation has the potential to help people get into a state of mind for cognitive reappraisal [13, 24, 29]. According to Jon Kabat-Zinn, one of the founders of secular mindfulness meditation, paying attention to the present moment non-judgmentally can be practiced through paying attention to the act of breathing [54-56]. Deep breathing has shown many benefits for emotional regulation, and researchers have shown ATB can be used to refresh the mind and decreases the negative effects of emotional experiences [96].

\subsection{Emotional Regulation Technology in HCI}

Researchers in HCI have explored how technology inventions can assist people with emotional regulation to improve their health and well-being using various emotion regulation strategies [16$18,33,53]$. Using notifications is one strategy popularised in commercial devices and apps. For instance, The Bellabeat [7], not only can track steps and other pieces of body data similar to other wearable sensors but also tracks breathing with a core focus on encouraging deep diaphragmatic breathing during mindfulness meditation. Sadka and Antle [89] conducted a literature review looking at opportunities and challenges for designing for emotional regulation in HCI. Important points to note are firstly, there are no clear guidelines for visual representations of emotional data. Secondly, the researchers noted that there were challenges in providing both representation of emotional data in the moment and periods of reflection after the experience. Through the process and the collection of first-person data, we propose a new method which will both provide real-time data and a reflective period of the experience which will help inform the design of the prototype.

Looking at the design and development of wearable technology for emotional regulation in $\mathrm{HCI}$ for adults, there are two notable projects that can be discussed to understand opportunities for future development in the space. Hao et al. [42] developed a braincomputer interface which collected the user's emotional arousal data and translated it to LED lights on a bracelet. The researchers noted that the participants did not know how to regulate their emotions in a short time period in a lab setting. The researchers 
focused on visualizing emotional arousal which is a common practice in wearable technology. We are interested in combining the visualization of emotional arousal data in a wearable with a positive coping strategy to support periods of high arousal. There was no discussion in the study on changing the behaviour of their participants. Azevedo et al. [4] developed doppel, a wearable device which sent the user a calming pulse whenever their emotional arousal increased due to writing and presenting a speech. Overall the device seemed to positively calm the participants during an emotionally intense activity. However, it is unclear how the device would be implemented outside of the lab as the study was a one-off event and was not tested outside the lab.

To our knowledge there are limited studies in HCI that have designed and developed screenless wearable prototypes from the lived experience of participants to support emotional regulation. Our research addresses this gap to explore how first-person data can be collected to inform the design and development of a wearable for emotional regulation.

\subsection{Wearable technology and jewelry}

Jewelry practitioners and researchers have looked at how jewelry can be both fashionable and functional. Jewelry is one of the oldest craft practices in the world, and with the popularity of wearable technology, craftspeople are beginning to modernize their practice [59]. Koulidou and Mitchell [59] emphasized how there has been a heavy focus on wearable technology development in HCI, rather than the message of the piece. They also note that wearable technology has the potential to work beyond "wealth, class, conformity or aesthetic display ... [and can showcase their personal values along with] a number of questions concerned with preciousness, identity and wearability" [59, p. 2]. Similarly, a strong critique of wearable technology in HCI by Jain [50] is the focus on technology development, rather than wearability. However, design researchers are shifting to more creative works that bring back the values of traditional jewelry making.

Heiss et al. [44] co-designed a necklace that monitored the heart. They argue that co-designing with craftspeople, engineers, and health practitioners from the beginning of the design process creates more interesting and aesthetically pleasing pieces of wearable technology. Wallace et al. [105] developed a piece of jewelry that rotated through images of a deceased person that gives the user personal emotional values and significance with the piece of wearable technology. Frey et al. [27] developed a pendant where the wearer aligns their breath with the fading LEDs; a similar strategy to our use of ATB, yet we delve deeper into personal preferences regarding the public visibility of emotional data. HCI researchers are at the beginnings of conversations around the opposition to standardization and the support of diversification [40,101], towards bespoke and personalised technology designs.

However, more design exploration in $\mathrm{HCI}$ could push these ideas of co-design further by engaging the user in the design process and assist them in developing their own piece of technology to support their own body, emotions, and materiality needs. Spiel [101] emphasizes that traditionally, designs represent a constrained set of bodies and there is a need to look at a broad range of representations - there is no singular body and everybody is significant. Designers should consider the uniqueness of the body. There are opportunities to build upon current literature using first-person research methods to develop unique pieces of technology that are meaningful for the wearer and assist in the self-regulation process of emotional regulation.

\subsection{First Person Research in HCI}

In this paper, we are defining first-person research as study of the subjective self in terms of "the lived experience associated with cognitive and mental events" [104, p. 1]. In HCI, there has been an increase in research that uses first-person enquiry to help define personal experiences while using technology [68]. An emerging research-through-design approach in HCI is first-person. However, using the prototype by the researchers often goes unreported in papers [45]. The first-person design process leverages long-term usage of design prototypes that supports fast tinkering in an early innovation stage and helps develop unique new design ideas. It also helps reveal real needs from detailed and subtle understanding, which might be hard for other methods to discover through the data as analysis might find these moments unremarkable [48, 68, 107]. In addition, the approach itself provides a process to enhance self-awareness and understanding. Other researchers have recalled that the design and development of their prototype in first-person research helped them look at their own practice in a different light. For instance, Reed and McPherson note that through a first-person account, they gained the ability to measure and become aware of unconscious actions that became visible while interacting with the prototype [87].

Popular ways first-person methods have been formally reported in HCI include when the researchers use the prototype in their own homes [12, 23, 68, 76] and somatic design [15, 45, 48]. Somatic design, sometimes called soma design or somaesthetic design, is a design approach where the prototypes are developed through explorations with the body and movement [93]. The subjectivity of individual body experience and the related topics of physical and emotional uniqueness has brought attention to first-person study for designing wearables [48]. However, there is limited detail on how the first-person methods are formally used in the design process of the prototype as papers do not extensively discuss the iterative process, do not report on the initial design and development phase, nor use the first-person method to test an already developed prototype.

Within first-person data collection methods, HCI researchers often focus on using extensive interview techniques to understand the lived experience with the prototype $[12,23,68,76]$. For example, Cas and Zhang [92] interviewed nine designers about their emotions during their design process, whereas Heshmat, Neustaedter and Debrincat [45] developed extensive interview questions to understand how Monuments, an always-on video recorder integrated into the homes of the researchers. However, we were interested in looking at alternative data collection methods that are easy to administer without other researchers being involved in the daily collection of data. We began looking at other phenomenological data collection methods and how the research methods have been used in HCI research. Along with interviews, Cochrane et al. [15] designed an Inside-Out Probe workbook that was used as a probe in the 


\section{Phase 1: Data Collection with Workbook 1

- Day 1 Task: with prototype version 1

- Day 2 to Day 16 Task: with prototype version 2

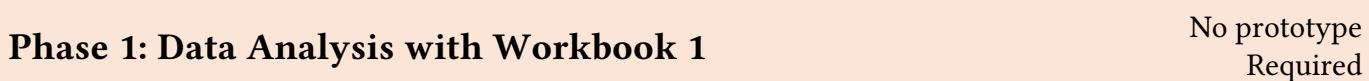

- POMS-SF results calculate the total mood disturbance (TMD) score to identify the emotion that needs assistance.

- All visual data (drawing, texture, model) are categorized based on emotions and tasks (happy, sad, anger, fear, social experiment, calm).

- Use the thematic analysis method to analyse all the text data (stream of consciousness writing, open-ended questions).

\section{Phase 2: Iterative Design Process}

- Iteration 1, 2 and 3

\section{Phase 3: Prototype Testing with Workbook 2}

- Day 1 to Day 8: with prototype version 3.

\section{Phase 3: Data Analysis with Workbook 2}

No prototype required

- POMS-SF results calculate the total mood disturbance (TMD) score. Compare to the result from workbook 1.

- Use the thematic analysis method to analyse all the text data (stream of consciousness writing, open-ended questions). Compare the result to Phase 1.

- Layering the body map of Fear and Anger, compare to the layering body map of all the Mindfulness practices.

Figure 2: Process diagram of the whole study split up into three phases.

interview during five workshops with novice and expert walking meditation practitioners. The Inside-Out Probe workbook (which included a non-judgmental stream of consciousness writing, written questions, and body mapping) was of interest to our research due to the accessibility of potentially using a similar method to collect daily lived experience data. Originally developed for healthcare treatment and assessment, body maps give users an outline of the body where they can sketch or write any notes about bodily experiences during a specific experience [21, 25, 73, 79, 90, 91]. In $\mathrm{HCI}$, body maps are becoming popular in somatic research and soma design, especially in the design of wearable technology to understand lived bodily experiences. For instance, Søndergaard et al. [99] developed a prototyping kit titled Menarche Bits which can be used by young adolescents to create wearable technology for their menstruating bodies. The kit was initially developed through movement practices and sketching body maps. Another method used in the exploratory process before the initial design of a prototype is Mah, Loke and Hespanhol's [69] first-person research approach that included documenting the practice of a daily compassion cultivation technique using stream of consciousness writing and body maps after each session. The study is notable for the contemplative framework that highlights the need for mind training of the designer/researcher to more keenly be able to self-observe the dynamic patterns of cognitive, emotional and somatic experience. Of particular relevance for our study is their recommendation to carefully consider the intensity and timing of the self-observation sessions for data collection, with regards to the well-being of the design researcher. 
Phase One Inside-Out Probe Workbook

\section{Emotional Activity Probe Content}

Mindfulness Practice Probe Content

Q1. The stream of consciousness writing task: "No rules, no judgement, no grammar...simple write whatever comes to mind. Spend 5 - 10 minutes on this".

Q2. The stream of consciousness drawing task: "No rules, no judgement...simply drawing whatever comes to mind to create an image. Spend 2-5 minutes on this".

Q3. The stream of consciousness texture task: "No rules, no judgement... using paper to create any texture to represent your feeling. Spend 2-5 minutes on this".

Q4. The stream of consciousness paper modelling task: "No rules, no judgement... using any material to create a rough 3D model. You can incorporate the data above. Spend 2-5 minutes on this".

Q5. Body maps: "Visual markings of self-observation of body state, with textual annotations. Use colour pencils and a pen. Spend about 5 minutes on this".

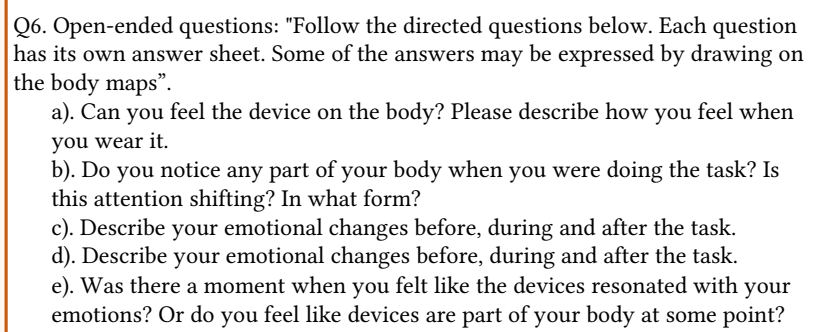

Q7. Post-Short form of the Profile of mood states (POMS-SF) self-test.
Q6. Open-ended questions: "Follow the directed questions below. Each question has its own answer sheet. Some of the answers may be expressed by drawing on the body maps".

a). Describe your thoughts during the task activity

b). Do you notice any part of your body when you sit still? Is this attention shifting? In what form?

c). Describe your emotional changes before, during and after the task d). Do you feel the urge to express your emotions? Record any body movement or behaviour.

Figure 3: The Inside-Out Probe Workbook data collection for phase one

\section{STUDY DESIGN}

To explore how designing for the self can produce bespoke wearables that support personalized emotion regulation, we set up a first-person autobiographical design study of the design researcher. For this study, we focused on understanding the lived experience of emotional activities and the positive coping strategy of ATB. It is important to point out that the researcher whose data was collected in the study does not have any diagnosed mental health or addictions, and instead wanted to develop a prototype to help strengthen their emotional regulation to cope with daily stress.

The three month long study was structured into three main phases (Figure 2). Phase one involved a period of self-observation and documentation of emotion-triggering activities to understand the lived experience of emotions, and to identify opportunities and preferences for emotional self-regulation strategies. The Inside-Out Probe method provided a structured approach to data collection, including journalling and sketching. It is based on the work of Cochrane et al. [15], adapted for this study with additional data collection and designerly methods that can be used to inform the design of a piece of wearable technology for emotional regulation. The first version of the prototype was worn to collect arousal data, using a galvanic skin response (GSR) sensor attached to the left hand. Version 2 added a single RGB LED, which was programmed to display red (high arousal) or blue (low arousal) depending on the arousal data measured. It formed the basis of the input and output system of the evolving prototype. Phase two involved design work of ideation, material exploration and prototyping of a piece of wearable technology for emotional self-regulation, informed by the findings of the previous phase. It resulted in prototype version
3, the Breathing Scarf. A force sensor was added to measure breathing through belly expansion/contraction. Table 1 summarises the versions of the prototypes. Phase three involved self-testing and evaluation of the wearable prototype (version 3), following a similar method to Phase one.

In the following sections, we will introduce the procedures and methods for each phase then the results.

\section{PHASE ONE: UNDERSTANDING EMOTIONAL EXPERIENCES}

Phase one consisted of the design researcher participating in a structured daily activity and filling out the Inside-Out Probe workbook for 16 days, alternating between days where the researcher participated in emotionally tolling everyday activities or in the positive coping strategy of ATB. Each of the daily activities ranged from 30 minutes to 1 hour. The reason for the alternating days was twofold. Firstly, it helped the researcher reset and take care of their mental and emotional well-being. Secondly, the ATB exercises data can be compared to the emotionally everyday taxing activities to help understand the difference between emotionally intense and calm experiences. This data helped inform the design of the prototype.

In phase one, the design researcher explored emotional trigger tasks for four basic emotional experiences, including happiness, sadness, fear, and anger. The tasks were based on the "Three Primary Color Model of Basic Emotions [37], which stimulate the four basic emotions of "happiness," "sadness," "fear and anger" through "reward," "punishment" and "stress." This helped us explore which emotions will be used to inform the design of the prototype. Details 
on the activities can be found in Table 2. After the emotional activity, she listened to a 3-minute mindfulness exercise called "Calming Anxiety" on the Calm mobile application [64]. During overwhelming emotions, we sometimes become "numb or distract ourselves away from [the emotion]" [32, p. xv] which would make it difficult to use the workbook. Therefore, we used the 3-minute mindfulness exercise to refocus and be able to properly recall the activity. Once focused, she filled out the Inside-Out Probe workbook. During the mindfulness activity, she listened to the "deep concentration" mindfulness exercises for 20 minutes on the Calm mobile application. Both exercises of the app were narrated ATB exercises.

\subsection{Inside-Out Probe Workbook}

The Inside-Out Probe Workbook was filled out every day after each exercise (Figure 3). It consisted of a stream of consciousness writing exercise, sketching, design paper textures, and paper models of the experience, body mapping, open-ended questions (different questions for emotional activity and mindfulness), and the short form of the Profile of Mood States (POMS-SF). POMS-SF is a 37-item questionnaire that is commonly used to measure psychological distress[20]. Studies proved that this short version test could provide a valid alternative to the original version of POSM[20].

\subsection{Analysis of Phase One Data}

Thematic analysis is "a method for identifying, analyzing, and reporting patterns (themes) within data. It minimally organizes and describes your data set in (rich) detail" [8, p. 6]. It is a method that has been widely used for qualitative research $[8,38]$. The stream of consciousness writing and five open-ended questions were independently coded using thematic analysis by the first and second author. Codes from the emotional and mindfulness activities were coded separately.

The result of POSM-SF is used to calculate the Total Mood Disturbance (TMD) score, which refers to negative mood and has been widely used in psychology $[14,83]$.The process of calculation was based on that of Nanayama Tanaka et al. [75]. The POSM-SF result can indicate seven emotional states, which include Anger-Hostility $(\mathrm{AH})$, Confusion-Bewilderment (CB), Depression-Dejection (DD), Fatigue-Inertia (FI), Vigor-activity (VA), and Friendliness (F). The measurement formula of TMD is $(\mathrm{AH}+\mathrm{CB}+\mathrm{DD}+\mathrm{FI}+\mathrm{TA})-\mathrm{VA}$ The value of TMD represents the scale of negative emotions from the participant; the higher the TMD, the more negative emotions the participant experienced.

The purpose of the visual data in this study is to inform the design and find the design researcher's visual language and aesthetic preference. For this purpose, the raw visual data from the sketches, texture and models were classified according to different emotions, and the visual data were developed and recreated through the collage of the data to obtain more abstract visual representations of emotions. Then, the design researcher reflected on the analyzed data and described the visual development image with words. It mainly reflects the four categories of "shape," "texture," "color," and "material," as they are essential for the design. We established a simple visual database based on the reflection text. Finally, the research team developed the prototype from the visual preference analysis.

\section{PHASE ONE: RESULT}

\subsection{Key Themes Describing Emotional and Mindfulness Experiences from Phase One Inside-Out Probe Workbook}

Attention. We coded the first theme "attention" in both the emotional activities probe and mindfulness activities probe. With the emotional activities, during intense emotional situations, the attention was primarily focused on the body, whereas on calm days, the attention was primarily focused on the activity or environment, not on emotions or the prototype. For instance, in moments of calmness (such as day 3's activity of watching a comedy movie), the researcher was "very focused on the comedy, [and] did not feel the device on [her] body". Whereas on day 9 during the angry activity, the researcher could "hear tiny little sounds in [her] room, and [she] wanted to cover [herself] with a blanket to give [her] some emotional support."

During the ATB mindfulness activity, at first it was difficult to focus on the meditation practice. However, every day except one day, she was able to refocus her mind to her breath. On day 2 she reported she "had nothing to think about, and [she] felt hungry. It's a little difficult to concentrate while doing mindfulness, but the longer [she] spent on mindfulness, the more focused [she became]". Day 10 was the only day that she could not focus on the mindfulness practice. "Because I was dealing with something that made me angry before I started Mindfulness ... I need to calm down and stay focused, but it seems like I can't calm down, I can't clear my mind". Some days are distracting, and it can be difficult to get into the practice. However, there are opportunities on days that are difficult to calm down to use a wearable prototype to help support breathing exercises.

In the data, there are opportunities to support the researcher through the prototype by shifting the attention from negative emotional experiences to a focus on the prototype and encourage positive coping strategies. Most days the researcher found ATB supported emotional regulation. During days 13 and 15, when her emotions were difficult to handle, she decided to start focusing on her breath. When she calmed down, the light shifted to blue LEDs, which were programmed to turn blue in response to a lower arousal reading from the galvanic skin response sensor.

Breathing. The second theme "breathing" was found in both the emotional activities probe and mindfulness activities probe. The design researcher's attention was directed to her breath as recorded in her reflection in the Inside-Out Probe Workbook. At the beginning of the data collection period, breathing was a core focus during the ATB mindfulness activities. During calm mindfulness activities, there was a focus on breathing movement and circulation, whereas in negative emotional activities, there was shortness in the breath. During day 2 the researcher reports "Most of the time, I am counting my breath. After taking a deep breath, my attention starts to focus on my chest, and my neck can feel waves of energy where I breathe." During emotional experiences, such as day 10 during the mindfulness exercise, the researcher found her breath was short and there are opportunities to develop a prototype to focus on the breath to encourage a calm and relaxed state of mind. In the emotional activity probe, breathing was not reported until days 


\begin{tabular}{|c|c|c|c|c|}
\hline Days & Task & Triggered emotion & Test environment & Prototype version \\
\hline 1 & Eat a sweet dessert & Happy & Indoor & V1 \\
\hline 2 & Mindfulness Practice & Calm & Indoor & V2 \\
\hline 3 & Read a sad story & Sad & Indoor & V2 \\
\hline 4 & Mindfulness Practice & Calm & Indoor & V2 \\
\hline 5 & Watching a comedy for an hour & Happy & Indoor & $\mathrm{V} 2$ \\
\hline 6 & Mindfulness Practice & Calm & Indoor & V2 \\
\hline 7 & A day of fasting & Anger & Indoor & $\mathrm{V} 2$ \\
\hline 8 & Mindfulness Practice & Calm & Indoor & $\mathrm{V} 2$ \\
\hline 9 & Watch a horror movie for an hour & Fear & Indoor & V2 \\
\hline 10 & Mindfulness Practice & Calm & Indoor & $\mathrm{V} 2$ \\
\hline 11 & Wear the devices and talk to someone & Social experiment & Outside & V2 \\
\hline 12 & Mindfulness Practice & Calm & Indoor & $\mathrm{V} 2$ \\
\hline 13 & Watching a sad movie for an hour & Sad & Indoor & $\mathrm{V} 2$ \\
\hline 14 & Mindfulness Practice & Calm & Indoor & V2 \\
\hline 15 & Wear the device and walk on the street for 30 mins & Social experiment & Outside & V2 \\
\hline 16 & Mindfulness Practice & Calm & Indoor & $\mathrm{V} 2$ \\
\hline
\end{tabular}

Table 2: Daily Tasks for Inside-Out Probe Workbook for phase one.

13 and 15. The researcher found that she had support during the breathing exercises and wanted to embed that into the prototype. The researcher felt that the LED output of the prototype validated her emotional arousal level, and encouraged her to initiate ATB when her emotional arousal was high. On Day 15, she commented, "when [I saw the] red LED light-up to alert me, I felt as if it was a friend who was trying to help and support me ... the design gave me an alarm and notified my negative emotions, which broke my concentration with the emotion so my anger could stay in a comfortable range. When the blue LED lit up, I felt more connected to my breath and it helped me calm down."

Body Awareness. The theme "body awareness" appears in both the emotional and mindfulness activity probes. Body awareness was defined by anytime that the researcher was aware of her body [49]. During the emotional activities, the researcher reported a strong focus on the body and a need for support during overwhelming emotional situations. During positive emotional activities, the researcher reported an awareness of the device. For example, during Day 11 on a calm activity, the researcher commented that she felt her "arm and hand and wanted to keep the device in place." Whereas during negative emotional activities, the researcher ignored the device. During fear activities, she could feel her heartbeat, while in angry situations she reported her body felt heavier. There are opportunities for the prototype to physically support the body during emotional activities.

During the ATB mindfulness activities, there was a shift of body awareness between focus on the breath where the researcher reported she was fully immersed in ATB. When distracted (often by the environment) or if she was struggling to focus on the practice, she reported attention on her face and hands. During moments of distraction, she reported that she was more aware of the prototype connected to her hand. For example, on day 6 she reported, "I'm not paying attention, and I can always feel my left hand wearing the device."

Emotional Connection. We coded the theme "emotional connection" when the researcher reported on emotion during both types of activities. During the emotional activities, she reported that it was difficult to shift her attention from the emotions and body to a calmer and collected state. On day 5 during the sad activity, the researcher reported that the sadness felt like "tiny needles pricking out of [her] chest" and she could only feel herself and her feelings. She found it difficult to recover from that state. There are opportunities for the prototype to bring a person out of her negative emotional experiences. Even with one LED light which can sometimes be difficult to alert the researcher of a change in emotional 


\begin{tabular}{|c|c|c|c|c|}
\hline & Anger Emotional Collage & Fear Emotional Collage & Mindfulness Collage & Mindfulness Collage \\
\hline $\begin{array}{c}\text { Categorise/ } \\
\text { Collage }\end{array}$ & Shape & $\begin{array}{c}\text { Messy shape, home in the } \\
\text { centre, needle. }\end{array}$ & $\begin{array}{c}\text { The mesh, the fence, raised, } \\
\text { sharp spines }\end{array}$ & $\begin{array}{c}\text { Organic, stack, line, repeated } \\
\text { pattern, Like seaweed, up and } \\
\text { down }\end{array}$ \\
\hline Texture & Moist, greasy, soft. & Hard, Sharp, with gaps & $\begin{array}{c}\text { Smooth, soft, flowing line, } \\
\text { bouncy and solid }\end{array}$ & $\begin{array}{c}\text { Soft and flat. More like a flat } \\
\text { pattern }\end{array}$ \\
\hline Colour & $\begin{array}{c}\text { Black and red, strong colour } \\
\text { contrast, colour shading. }\end{array}$ & Strong colour contrast & $\begin{array}{c}\text { Light blue, white with a bright } \\
\text { colour in the centre (yellow } \\
\text { and red) }\end{array}$ & $\begin{array}{c}\text { Blue and light grey with some } \\
\text { white colour }\end{array}$ \\
\hline Material & Like mud, creamy. & Cotton, tread net, hard thorns & Clay, cotton, thread, plastic & Thin fabric, thread \\
\hline
\end{tabular}

Table 3: Two examples of emotional activity collages and two examples of mindfulness collages where we merged the data from the sketches, textures, and 3D physical models.

arousal, she was able to notice it on day 15 where she successfully practiced ATB during anger.

External Distraction. The theme "external distraction" can be defined as any factors outside the control of the researcher. For the emotional and mindfulness activity probes, the researcher reported external distraction that obstructed her emotional regulation capability. During the emotional exercises, the researcher decided to experiment to see if there were any opportunities to design a prototype to be used both inside and outside the home. Wearing the prototype outside the home, she reported insecurity and social pressure. During the activities outside the home, she felt highly insecure, and people were looking at her more often than usual. Even though random people on the street were not aware of the colour meanings on day 11 , she felt that they were "looking directly at [her] inner emotions." However, in the home she felt the LEDs were a great way to support her emotions. During the ATB mindfulness activities, the design researcher reported that smelling food outside her apartment distracted her practice on days 6, 8, 14 and 16, which distracted her from her breath.

\subsection{Stream of Consciousness Sketches, Textures, and Models}

We separated the sketches, textures, and 3D physical models into emotional activities and mindfulness activities. Then we created multiple collages that represented the visual data collected from the mindfulness activities. For the emotional activities we created collages for each emotion. After designing the collages, we categorized the collages into themes of shape, texture, color and materials. Table 3 showcases two collages from the emotional activity probe and two from the mindfulness activity probe. The collages were used as visual inspiration for prototype version 3.
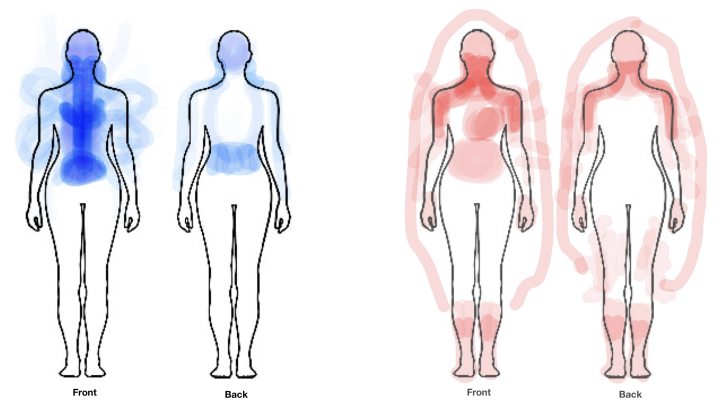

Figure 4: Layered body maps of mindfulness practices (left) and fear and anger emotional activities (right).

\subsection{Body Map}

Through the written data, we can see there is a need for support during emotionally intense negative experiences. Therefore, to inform the design of the final prototype, we overlapped the mindfulness body maps and compared them to the most intense emotional activities, which were fear and anger. Looking at the body maps (Figure 4), we can see there is a lot of energy emanating out from the body during the anger and fear emotional activities, whereas in mindfulness, there is a stronger focus internally. This informed us of our placement of the wearable prototype. Through the data, we decided to design a scarf that could be wrapped around the upper body to support emotional experiences.

\subsection{Body Storming}

After analyzing the data from phase one Inside-Out Probe Workbook, it was unclear as to the optimal location of the scarf on the upper body. We decided to do a quick body storming activity to rate three 


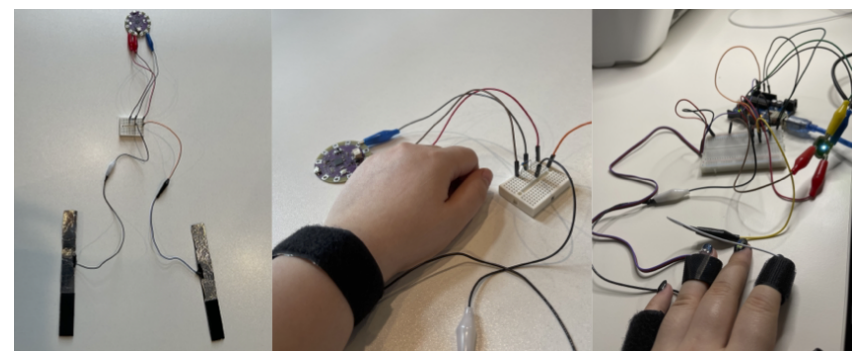

Figure 5: Images of the prototype V1 (Left and Middle) and V2 (Right) displaying a blue LED which shows low emotional arousal from the GSR.

different statements on a scale of 1 to 5 , where 5 is strongly agree. After the activity, we designed the prototype to drape across the shoulders and hang down in the front of the body.

\subsection{Short Form of Profile of Mood State (POMS-SF) Phase One Inside-Out Probe Workbook}

The TMD score will show which activity has more negative moods to identify the emotion that needs assistance and inform design decisions. A higher TMD score represents higher negative moods. During the mindfulness activities, the TMD scores had an average of 3.4. During the design researcher's anger and fear emotional activities, she had a TMD average of 24 . The TMD average for sadness, happiness and the social experiment tasks were 12.8, 7.5, and 10.3. Compared with the TMD score for calm emotion (Mindfulness activity), fear and anger had the highest TMD score, indicating that the design researcher needs assistance to regulate emotions of fear and anger.

\section{PHASE TWO: ITERATIVE DESIGN OF THE PROTOTYPE}

We began looking at the Inside-Out Probe Workbook data to inform the design of a prototype for the design researcher to use in phase three. The analysis above yielded that fear and anger were the most unstable emotions, and thus given priority in the subsequent design phase. The findings from the analysis of the data helped to inform the design of a wearable scarf that used galvanic skin response and breathing data to trigger an LED guided breathing exercise.

\subsection{Prototypes}

We used two different prototypes while exploring emotional and mindfulness activities. We built the first prototype (Figure 5) from Thomas Kosch's Galvanic Skin Response powered by Arduino tutorial [58]. We replaced the Arduino UNO open-source electronics with a Lilypad. But we were using all the other electronic and material components in the tutorial. We modified the code presented in the tutorial and wrote our own code in Processing to record the data. The second prototype (Figure 5) included a Lilypad single LED which we programmed using the Arduino IDE. When the emotional arousal was low $(<80)$, the LED light would turn blue, during medium emotional arousal, the LEDs would turn purple and during high emotional arousal, the LEDs would turn red.

\subsection{Body Storming}

Bodystorming is supported by theories of embodied cognition [80, $94,95]$; it requires designers to simulate or imagine the product and use scenario. In this study, we are carrying out a bodystorming practice based on Schleicher's first way of using bodystorming: "working the space or place in which the product you are designing will ultimately be used" [94, p. 1]. We tested different ways to wear the scarf and rated three categories: "comfort," "safety," and "wearability" according to the wearing experience, with 0 as the lowest score, and 5 as the highest score. This helped inform the placement of the scarf (Table 4).

Results are reported for phase two Inside-Out Probe Workbook and presented in the final prototype section below.

\section{PHASE TWO: FINAL PROTOTYPE}

By analyzing the data from phase one Inside-Out Probe Workbook and the body storming activity, we built a final prototype (version 3) which we titled Breathing Scarf. The prototype is $152 \mathrm{~cm}$ by $24 \mathrm{~cm}$ with the fibre optics around $22 \mathrm{~cm}$ long. It is a scarf that encourages the positive coping strategy Attention To Breath (ATB) during emotionally taxing activities inside the home. The design went through a process of sketching and collage; examples in Figure 7 present how we generated the design on paper.

The final prototype includes a hand-made wool scarf made by the design researcher using a punch needle technique (Figure 1). The inside layer where the micro-controller (Arduino) is housed is set with silicone. There are a few holes in the scarf where the LEDs stick out with fiber optics connected to them (Figure 8). The work also includes two DIY GSR sensor pads (to track arousal) which are connected to the index and middle finger on the left hand. Finally, a stretchy piece of fabric is tied around the waist which holds a force sensor in place to track breathing (Figure 9).

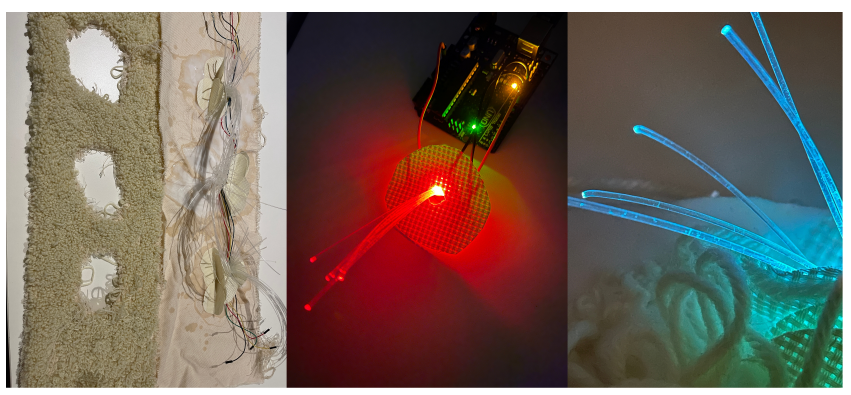

Figure 8: (Left) One side of the punch needle scarf showing the silicone center; (Middle) LED test of the light and fiber optic; (Right) Close up of a blue LED and fiber optics in the final prototype.

The Breathing Scarf worked by collecting real-time data through our DIY GSR sensor connected to the hand. The design researcher 


\section{Phase 2: Iterative Design Process}

\begin{tabular}{|l|}
\hline \multicolumn{1}{|c|}{ Iteration 1} \\
Based on POSM-SF and TMD \\
score, negative emotion: \\
Anger and fear need further \\
assistance.
\end{tabular}

\begin{tabular}{l}
\multicolumn{1}{c|}{ Iteration 2} \\
\begin{tabular}{|l|} 
Bodystorming, test different \\
ways to wear the scarf on the \\
upper body based on comfort, \\
safety and wearability.
\end{tabular} \\
\begin{tabular}{|l|} 
Reflect on the visual \\
development data and \\
describe the visual \\
development image based on \\
shape, texture, colour, and \\
material.
\end{tabular} \\
\begin{tabular}{|l|}
\hline $\begin{array}{l}\text { Choose the preferred } \\
\text { descriptions from shape, } \\
\text { texture, colour and material. }\end{array}$ \\
\hline
\end{tabular} \\
\hline $\begin{array}{l}\text { Sketches and collages of the } \\
\text { final design. }\end{array}$ \\
\hline
\end{tabular}

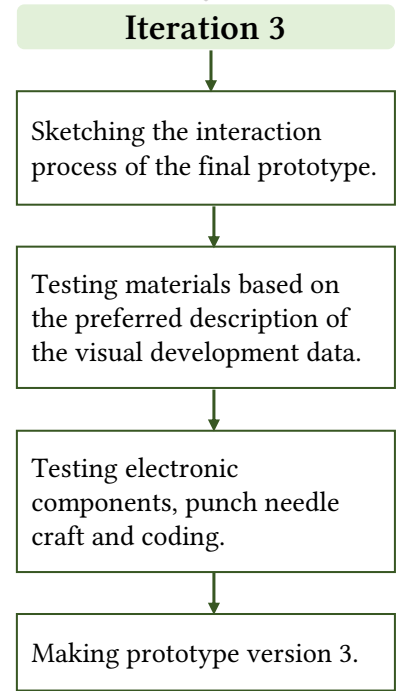

Making prototype version 3.

Figure 6: Showcase how the data from phase one inform the design of the Breathing scarf.

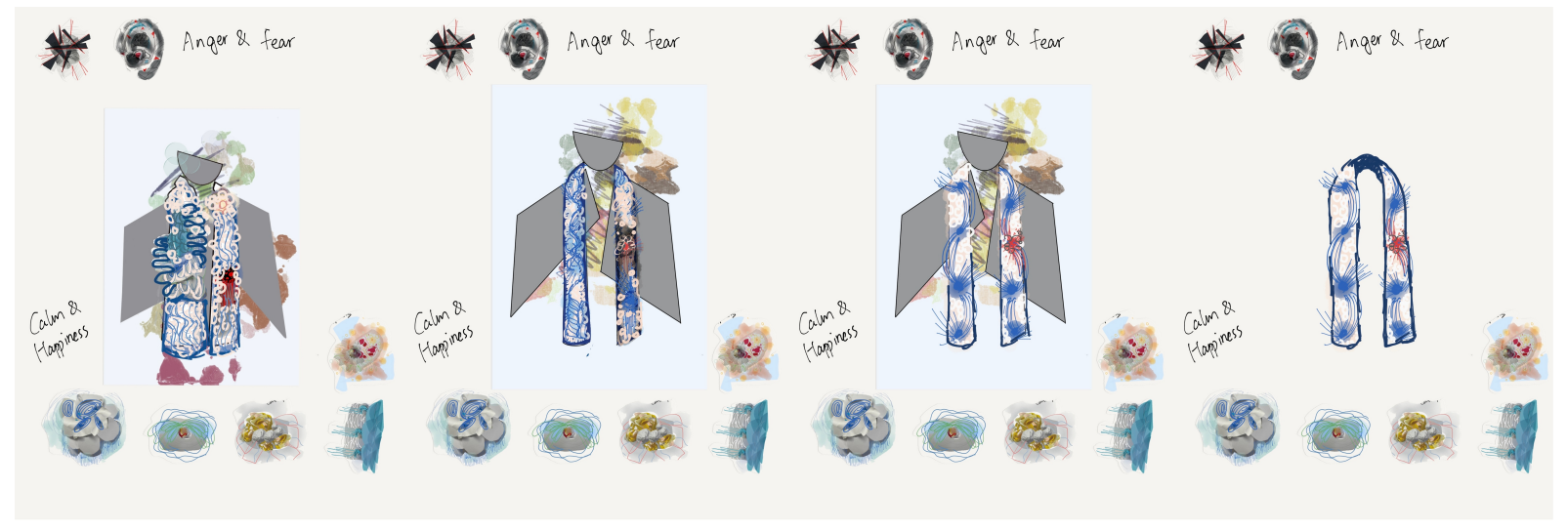

Figure 7: Sketches and collages of the Breathing Scarf.

wore it on her left hand while the scarf was wrapped around her neck. If the emotional arousal was above a specific threshold $(>80)$, then the LEDs on the prototype would blink red for a few seconds to alert her. Then using data from a force sensor connected to the stomach, the LEDs on the scarf would begin fading in and out in blue to match the wearer's breath and encourage the user to pay attention to their breath. After 30 seconds, the guided ATB exercise would finish (Figure 12).
The collages informed the design of the final prototype. Red was a prominent colour sketched during fear and anger emotional activities, whereas blue was a common colour seen in the mindfulness activities. Therefore, we decided to alert the researcher that their emotional arousal increased using the colour red but encourage the positive coping strategy of ATB using a softer blue colour. The design of the LEDs (which look like flowers) were inspired by the mindfulness sketches to encourage calmness and relaxation. 


\begin{tabular}{|l|c|c|c|c|c|}
\hline \multicolumn{1}{|c|}{ Categories/ score } \\
\hline $\begin{array}{l}\text { The location is very } \\
\text { comfortable }\end{array}$
\end{tabular}

Table 4: Rating six different positions of a scarf on body

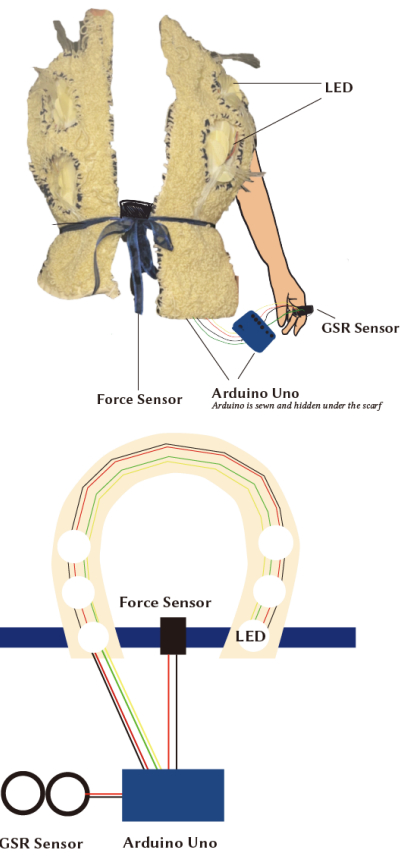

Figure 9: Diagram of the microcontroller and sensors on the Breathing scarf.

Rounded shapes are a personal preference of the design researcher and it helped after both mindfulness and emotionally taxing activities to draw organic flower-like shapes. The findings informed us that it might be helpful to include weight on the prototype to support the user during emotional experiences. The final design is in Figure 12. After the design and crafting of the prototype were complete, the design researcher wore the prototype for eight days and filled out the phase three Inside-Out Probe Workbook to evaluate the prototype and its impact on her capacity to regulate her emotions through ATB.

\section{PHASE THREE: EVALUATING THE PROTOTYPE DURING EMOTIONAL ACTIVITIES}

In phase three Inside-Out Probe Workbook, we removed the stream of consciousness sketching, textures, and materials because they were mainly used as a probe to inform the design of the prototype (Figure 10). The workbook consisted of the stream of consciousness writing, open-ended questions, and POM-SF scale. We collected data from the probe for eight days alternating from anger and sad tasks to mindfulness tasks. The activities ranged from 30 minutes to 1 hour. A schedule can be seen in Table 5 .

8.0.1 Phase Three Inside-Out Probe Workbook Analysis. The first and second author coded the data from the stream of consciousness writing and open-ended questions using thematic analysis. The original codes from phase one data analysis were used and adjusted as necessary.

\section{PHASE THREE RESULTS}

\subsection{Key Themes Describing Emotional Experiences from Phase Three Inside-Out Probe Workbook}

Attention. During the emotional activities in phase three documented in the Inside-Out Probe Workbook, there is an attention shift that happens during the lived experience between the taskat-hand, overwhelming emotions begin to intensify and then the activation of the Breathing Scarf assisted in the regulation of the emotions. Once the scarf was activated, the design researcher noted an attentional shift to a focus on the breath and it gave them the ability to stay calm. For example, during day 1, the scarf felt like "another person" that helped draw their attention away from an angry emotion and changed their mood to a calmer state. During the mindfulness activities, the scarf was less active. However, there was still a focus on the scarf's warmth and weight. On day 7, during the mindfulness exercise, the design researcher noted that she felt 


\section{Phase Three Inside-Out Probe Workbook}

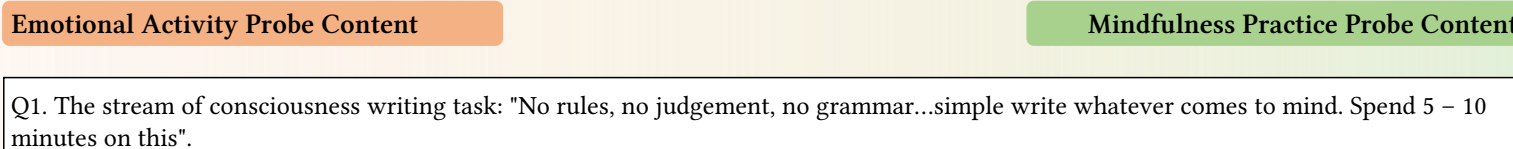
minutes on this".

Visual data removed for testing the final prototype.

Open-ended questions and Post-Short form of the Profile of mood states (POMS-SF) self-test are the same as Phase One.

Figure 10: The Inside-Out Probe Workbook data collection for phase three

\begin{tabular}{|c|c|c|c|c|}
\hline Days & Task & Triggered emotion & Test environment & Prototype version \\
\hline 1 & Mindfulness Practice & Calm & Indoor & $\mathrm{V} 3$ \\
\hline 2 & Watch social news for 30 minutes & Anger & Indoor & V3 \\
\hline 3 & Mindfulness Practice & Calm & Indoor & V3 \\
\hline 4 & Watch a horror movie for 1 hour & Fear & Indoor & V3 \\
\hline 5 & Mindfulness Practice & Calm & Indoor & V3 \\
\hline 6 & Watch horror live game for 1 hour & Fear & Indoor & $\mathrm{V} 3$ \\
\hline 7 & Mindfulness Practice & Calm & Indoor & V3 \\
\hline 8 & Read criminal case news for 30 minutes & Anger & Indoor & V3 \\
\hline
\end{tabular}

Table 5: Daily Task for Inside-Out Workbook for phase three.

"very warm under the scarf... it made [her] feel very safe". The prototype was triggered on mindfulness day 3 . She noted that she thought there was an issue with the code and tweaked the arousal levels a bit for the next day.

Body Awareness. During the emotional activities, the core focus of body awareness was on the upper body. The design researcher noted during a fear activity on day 4 that she felt the scarf was a shield and the prototype made her feel safe. Similar sensations were reported during the mindfulness activities where the pressure and weight made her focus on their upper body. On day 7 she reported that the prototype felt like a second skin.

Breathing. The design researcher discussed breathing in the workbook almost every day. She reported that she "deliberately adjusted their breath in order to see the [blue] light change." She found it simple to trigger ATB during the emotionally taxing activities. She also self-reported that she felt more oxygen was entering her body through deeper breaths.

Emotional Connection. The design researcher reported that she felt comfortable when the device was triggered during emotional activities. She felt it was easier to trigger ATB to help regulate their emotions. During day 8 she noted that she felt "angry, but when the LEDs light up, [she] noticed [her] emotions and adjusted their breathing." Even though she did report strong emotions during the task, it helped them feel "calm before and after the task." During the mindfulness tasks, the design researcher reported less emotional experiences during the practice, however, still felt connected to the prototype.

External Distraction. The research only reported external distraction during emotional activities. She reported she felt more focused on the task at hand and did not find external distractions distracting. She only reported noticing the scarf when her arousal increased, and she needed the support. The design researcher found it easy to shift between the task, the scarf, and her breath. On day 6 while watching a horror movie, she reported, "I followed the plot of the story wondering when something would scare me. At the same time, I felt physically safe, so I found the experience more exciting than scary". 

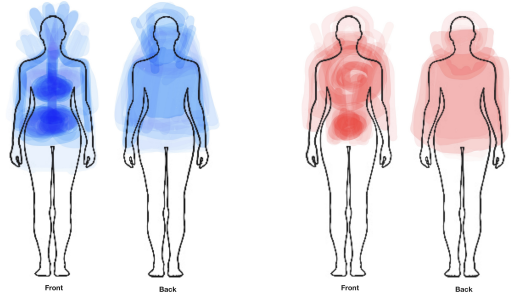

Figure 11: Merged body maps of the mindfulness exercises (left); merged body maps of the emotional activities (right).

9.1.1 Body Map. The body maps (Figure 11) showed that the core focus with both the mindfulness and emotional activities was on the upper body and the diaphragm. Compared with the body maps from the previous workbook, the central focus is within the body rather than externally. By looking at the figure of the body map, we can clearly see that the places that are covered by the scarf are the core bodily focus. The result suggests that after wearing the Breathing Scarf, the design researcher experienced less distraction from the external environment and more of a focus on the body.

\subsection{Short Form of Profile of Mood States (POMS-SF) Phase Three Inside-Out Probe Workbook}

The TMD results showed that the emotional and mindfulness activities had similar scores. The average for emotional activities was 3 , while mindfulness had an average of -1.75 . Our results demonstrated that by wearing the Breathing Scarf, the design researcher could better regulate their negative emotions and stay in a more calm emotional state.

\section{DISCUSSION}

We discuss a set of design considerations emerging from our study. In designing for one to support personalized self-regulation strategies, key considerations include designing for personal comfort and ownership, and individual-over-social meaning-making. We also reflect upon key concerns in the design research process of the well-being of the design researcher and their ability to self-regulate emotions, as well as the ethics of emotion work. The benefits and limitations of our first-person design research approach to inform the design of wearable technology to support emotional regulation are discussed, highlighting the value of self-reflection through journaling and sketching.

\subsection{Design considerations for wearable technologies to support emotional self-regulation}

10.1.1 Design for Personal Comfort. One aspect of the design we learned early on was that our prototype would not be suitable for outside use. The design researcher was interested in developing a prototype using LEDs as feedback for alerting them of their increased emotional arousal. However, when conducting social experiments, she became very nervous in social situations and made the decision that the prototype would be only used for emotional regulation inside the home. There has been a trend in using light and colour to inform users of changes in their biofeedback data (e.g., Hao et al.'s [41] wrist-wrist LED prototype). However, the wires and bright lights are not common practice in streetwear clothing, and made them feel as if she were the focus of the public's attention. In Phase One, the exaggerated and mechanical appearance of the prototype version 2 made the design researcher feel very uncomfortable in public spaces. The users in studies by Simm et al. [98] and Umair et al. [103] reported similar experiences when using their prototypes in public spaces. The social consequences of the public display of personal bio data is an important issue. We argue that it is important for designers and researchers to understand both the lived experience and use-case scenarios for their design concepts during the preliminary development of the prototype, to cater for personal preferences regarding private versus public display of the user's bio data.

10.1.2 Designing for Ownership. The design researcher found that overall the prototype assisted them in regulating their emotions during emotional activities in the home. She noted consistently that the prototype felt like a friend that was encouraging them to calm down during moments of anger or fear - almost as if the prototype was a second skin. Studies suggest that a sense of ownership can help reduce negative emotions and are associated with several indicators of emotional regulation, such as lowering stress response and the improvement of behavioral self-regulation [11, 52]. In our study, we found that the process of designing helped the design researcher feel ownership over the prototype and improved the experience she had with the device. Giving the ability to customize and develop their prototype themselves can give the user a sense of ownership and attachment to the prototype, enhancing feeling more connected to the technology.

10.1.3 Individual over sociocultural meaning of data display. Common in interface design is the use of standard conventions regarding the use and meaning of colours. In psychology there has been a great interest in research in colour preference. Researchers have found that colour preference is not universal and can greatly vary between different people, groups and cultures [102]. In Western society, red is often used to signal danger. However the same colour can have different meanings depending on the context and culture [2]. The design researcher purposely choose not to use cultural conventions for colours. In China (the home country of the design researcher) the colour red symbolises celebration and good luck. In our study, it is interesting to point out that the design researcher did create their own visual language through the sketches that was then transferred into the visual output of the wearable. The choice of colours was informed by personal preferences for how to express emotional experiences during the data collection, rather than sticking to conventional colour coding.

Given the purpose of the wearable was to support individual self-regulation of emotions by the wearer, it made sense for the colour choices of the interactive behavior of the LEDs to be firmly based on the wearer's preferences. Unlike the public display of data, where social meaning and interpretation must be taken into consideration in design [106], the private visual language of the user takes precedence. Contrary to typical user interface design where standardization of interface elements leads to high usability 


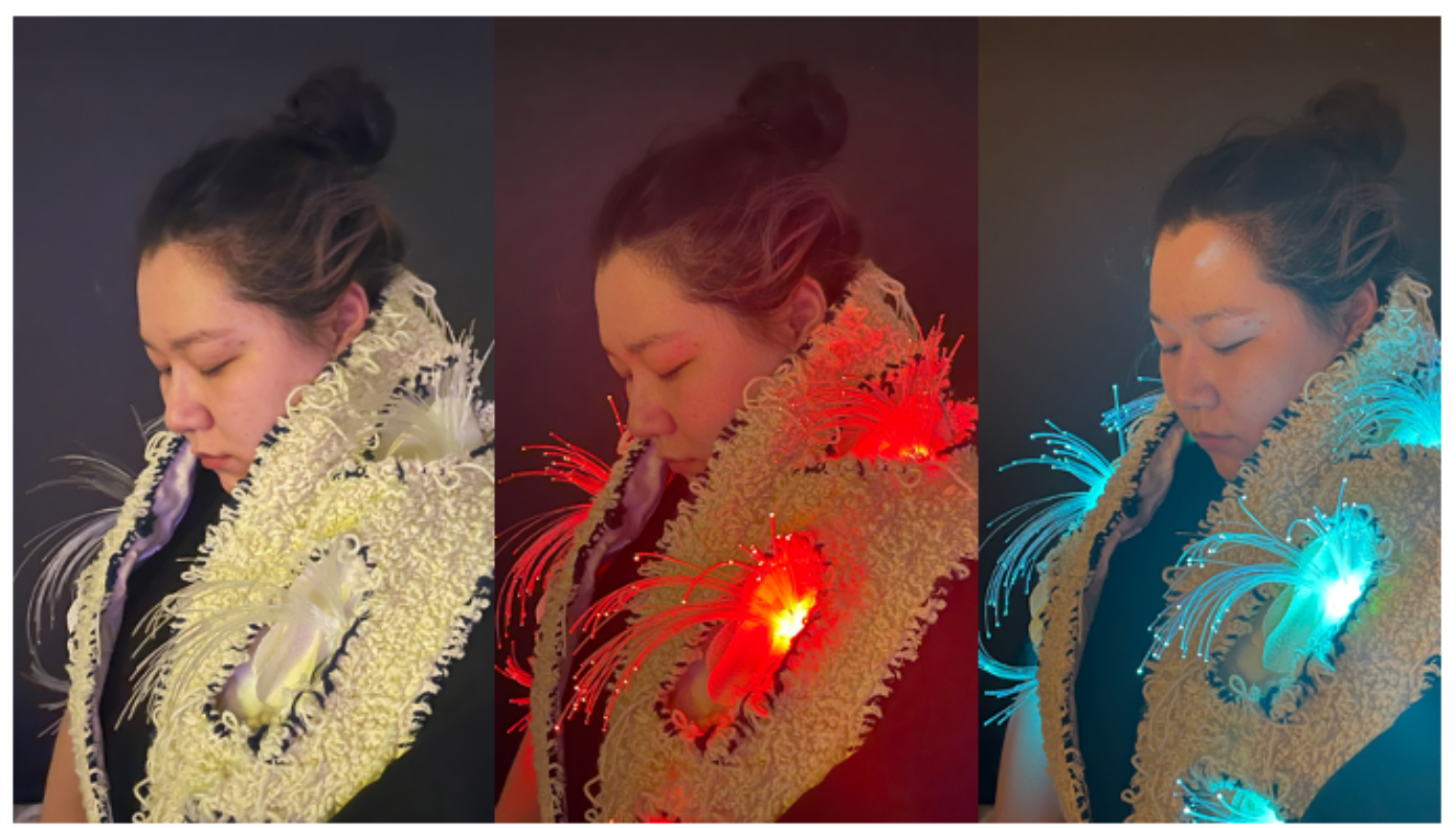

Figure 12: The final prototype Breathing Scarf showing different modes of the prototype: (Top) turned off; (Middle) in the alert mode; (Bottom) in the ATB mode.

across a broad population [77], customized wearable interfaces to support private display of data and feedback on emotional state can legitimately be open to mis-interpretation by the general public. In this context, obscuring personal bio data to public scrutiny is a valid safety strategy.

\subsection{Benefits and limitations of first-person design research methodology for emotional self-regulation technologies}

10.2.1 Taking care of the well-being of the design researcher. In the design of our study, we paid particular attention to the structure of the emotion-triggering activities that the researcher would be engaging in on a regular basis. We discussed the choice of emotions to trigger, and how they are triggered. We did not want the design researcher to experience emotional distress. To mitigate undesirable emotional repercussions, we elected to intertwine emotional activities with a mindfulness breathing exercise. The ATB exercise helped to calm the practitioner after strong emotion-inducing activities.

The ethics of emotion work for designers and researchers is raised by Hook et al. [48]. Not working alone is important for emotionally taxing design and research work, as the person can be emotionally vulnerable. As raised by Mah et al. [70], the individual researcher conducting first-person research on the self requires a support team to help motivate, debrief and make sense of what they are doing. In our study, we followed a similar process of regular meetings with the first and second author to check in on the wellbeing of the researcher, as well as provide guidance and support.
One of the challenges for future research is how to translate designing for one from the design researcher's lived emotional experience to co-designing with a client who wishes to incorporate an emotional self-regulation practice into a bespoke wearable. Can we ask clients to experiment with their emotional life and record their emotional experiences following our methodology, or does this ask too much of participants? An ethics of care in working with research participants is advocated by Howard and Irani [47], and similarly with design clients. One of the motivations for our first-person design researcher approach is to first test and evaluate our methods using our own bodies and emotional experiences, prior to co-designing with clients. In this way, we can carefully make ethical and methodological choices about what we ask our clients to do.

10.2.2 Encouraging Self-Reflection. The Inside-Out Probe Workbook assisted the researcher in documenting subconscious thoughts and behaviours that were invisible to them previously. The written reflection has opportunities to enhance the memories that could otherwise be incorrect or lack detail. In therapy practices, it is common practice to use journaling to facilitate meaning-making [65]. Our methodology is grounded in learning theory, especially in Wolfe and Kolb's experiential learning theory [109]. In their model, the researchers emphasize that learning happens through experiences with a period of reflection to gain a deeper understanding of the process.

Similarly, reflective writing and sketching has been shown to invoke self-reflection and assist in the development of a personal 
narrative [97]. Sketching helped the design researcher make critical design decisions such as the colors, materials, shapes, and textures of the prototype. The sketching, textures, and physical models shifted towards collages, which were iterated to develop the visuals of the scarf prototype. We encourage other researchers to implement journaling and sketching into their design process to understand the lived experience to develop more meaningful prototypes.

According to Sadka and Antle [89], there are challenges in emotional regulation technology to provide both live feedback and elements of reflection after the process. Our approach not only provides in-the-moment feedback for the design researcher when wearing the Breathing Scarf, but also the Inside-Out Probe provides moments of reflection after the activity to gain understanding of emotional patterns of behavior. For the design researcher the probe provided a structured format for reflecting on what worked well with the prototype, what environments and experiences the prototype can assist with, and what needs to be iterated in the design.

\subsection{Limitations}

It is important to emphasize that our first-person research method is about the lived experience of one researcher. As discussed, we are aware that the design and prototype might not be transferable to other designers, researchers or users. The intention of the work is to understand how this method could facilitate the design and development of a customized piece of wearable technology to support the individual user. Our method and other related HCI first-person methods are good tools for preliminary designs of prototypes $[23,76]$. Other researchers have recalled that the design and development of their prototype in first-person research helped them look at their own practice in a different light. For instance, Reed and McPherson note that through a first-person account, the researcher gained the ability to measure and become aware of unconscious actions that become visible while interacting with the prototype [87]. We also note that the bodymap outline we used in our study was of a "normal body", which abstracted away the unique characteristics of an individual's body. We did discuss this with the design researcher and she felt the most comfortable using these neutral outlines. Although it is important to represent all body types [101], in future studies, we recommend making it an individual choice option for the design researcher to draw their own body map outline based on their body type, so that it is represented in the design process.

\section{CONCLUSION}

Our contributions include a research-through-design case study, a design research methodology suited to exploring emotional experiences and self-regulation strategies, the Inside-Out Probe Workbook, and a hand-crafted wearable prototype that embodies the design considerations. In this paper, we presented our methodology for conducting first-person autobiographical design research to explore emotional self-regulation technologies. The methodology is unique for the intertwining of emotional activities and mindfulness exercises, as a strategy for controlling emotional repercussions for the design researcher. A core component of the methodology is the Inside-Out Probe Workbook. It is adapted from Cochrane et al. [15] by customizing it for the design space of emotional self-regulation, and adding designerly sketching activities for reflection and ideation. The workbook with its journalling and sketching activities helped probe the design researcher to understand the lived experience of emotionally challenging daily activities to inform the design process. The hand-crafted prototype The Breathing Scarf to support emotional self-regulation of the wearer emerged out of the design process, and embodies the design considerations of designing for personal comfort, ownership and individual-over-social meaningmaking. Though the methodology is still in its infancy, we see its potential for designers and researchers to collect first-person data on the lived experience of emotional life, to better inform the design of wearable technologies for emotional self-regulation and autonomy over individual health and well-being.

\section{ACKNOWLEDGMENTS}

We would firstly like to thank our friends and family for the support of the researchers during the study. This work was supported and funded by the National Sciences and Engineering Research Council of Canada (NSERC) through a Discovery grant (2017-06300) and a Discovery Accelerator Supplement (2017-507935).

\section{REFERENCES}

[1] Mirela A Aldea and Kenneth G Rice. 2006. The role of emotional dysregulation in perfectionism and psychological distress. fournal of counseling psychology 53 (2006), 498-510. Issue 4. https://doi.org/10.1037/0022-0167.53.4.498

[2] Aryaf Alnasuan. 2016. Color psychology. American research journal of humanities and social science 2016, 1 (2016), 1-6.

[3] Allison A Appleton, Eric B Loucks, Stephen L Buka, and Laura D Kubzansky. 2014. Divergent Associations of Antecedent- and Response-Focused Emotion Regulation Strategies with Midlife Cardiovascular Disease Risk. Annals of Behavioral Medicine 48 (10 2014), 246-255. Issue 2. https://doi.org/10.1007/ S12160-014-9600-4

[4] Ruben T Azevedo, Nell Bennett, Andreas Bilicki, Jack Hooper, Fotini Markopoulou, and Manos Tsakiris. 2017. The calming effect of a new wearable device during the anticipation of public speech. Scientific reports 7, 1 (2017), $1-7$.

[5] Ruth A Baer. 2015. Mindfulness-based treatment approaches: Clinician's guide to evidence base and applications. Elsevier, United States of America.

[6] Lisa Barrett, Batja Feldman, Kevin N. Ochsner Mesquita, and James J. Gross. 2007. The Experience of Emotion. Annual Review of Psychology 58 (1 2007), 373-403. Issue 1. https://doi.org/10.1146/annurev.psych.58.110405.085709

[7] The Bellabeat. 2017. How does it work? https://support.bellabeat.com/hc/enus/articles/115004149669-How-does-it-work-

[8] Virginia Braun and Victoria Clarke. 2006. Using thematic analysis in psychology. Qualitative Research in Psychology 3 (1 2006), 77-101. Issue 2. https://doi.org/ 10.1191/1478088706qp063oa

[9] Fred B Bryant. 1989. A Four-Factor Model of Perceived Control: Avoiding, Coping, Obtaining, and Savoring. Fournal of Personality 57 (12 1989), 773-797. Issue 4. https://doi.org/10.1111/j.1467-6494.1989.tb00494.x

[10] Carina Carbia, Séverine Lannoy, Pierre Maurage, Eduardo Lopez-Caneda, Kenneth J O'Riordan, Timothy G Dinan, and John F Cryan. 2021. A biological framework for emotional dysregulation in alcohol misuse: from gut to brain. Molecular Psychiatry 26 (2021), 1098-1118. Issue 4. https://doi.org/10.1038/s41380-02000970-6

[11] Jude Cassidy. 1994. EMOTION REGULATION: INFLUENCES OF ATTACHMENT RELATIONSHIPS. Monographs of the Society for Research in Child Development 59 (2 1994), 228-249. Issue 2-3. https://doi.org/10.1111/j.1540-5834.1994.tb01287. $\mathrm{x}$

[12] Wei-Chi Chien and Marc Hassenzahl. 2020. Technology-Mediated Relationship Maintenance in Romantic Long-Distance Relationships: An Autoethnographical Research through Design. Human-Computer Interaction 35 (5 2020), 240-287. Issue 3. https://doi.org/10.1080/07370024.2017.1401927

[13] Hyunju Cho, Seokjin Ryu, Jeeae Noh, and Jongsun Lee. 2016. The effectiveness of daily mindful breathing practices on test anxiety of students. PloS one 11 (2016), e0164822. Issue 10. https://doi.org/10.1371/journal.pone.0164822

[14] Han Byul Cho, Charles Elliott Bueler, Jennifer DiMuzio, Charlie Hicks-Little, Erin McGlade, In Kyoon Lyoo, and Deborah Yurgelun-Todd. 2018. Negative Mood States Correlate with Laterobasal Amygdala in Collegiate Football Players. 
BioMed Research International 2018 (2018), 1-11. https://doi.org/10.1155/2018 8142631

[15] Karen Cochrane, Lian Loke, Matthew Leete, Andrew Campbell, and Naseem Ahmadpour. 2021. Understanding the First Person Experience of Walking Mindfulness Meditation Facilitated by EEG Modulated Interactive Soundscape. In Proceedings of the Fifteenth International Conference on Tangible, Embedded, and Embodied Interaction (TEI '21). Association for Computing Machinery, New York, NY, USA, 1-17. https://doi.org/10.1145/3430524.3440637

[16] Dan Cosley, Victoria Schwanda Sosik, Johnathon Schultz, S Tejaswi Peesapati, and Soyoung Lee. 2012. Experiences with designing tools for everyday reminiscing. Human-Computer Interaction 27 (4 2012), 175-198. Issue 1-2. https://doi.org/10.1080/07370024.2012.656047

[17] Jean Costa, Alexander T. Adams, Malte F. Jung, François Guimbretière, and Tanzeem Choudhury. 2016. EmotionCheck: Leveraging Bodily Signals and False Feedback to Regulate Our Emotions. In Proceedings of the 2016 ACM International foint Conference on Pervasive and Ubiquitous Computing (Heidelberg, Germany) (UbiComp '16). Association for Computing Machinery, New York, NY, USA, 758-769. https://doi.org/10.1145/2971648.2971752

[18] Jean Costa, Malte F. Jung, Mary Czerwinski, François Guimbretière, Trinh Le, and Tanzeem Choudhury. 2018. Regulating feelings during interpersonal conflicts by changing voice self-perception. Association for Computing Machinery, New York, NY, USA, 1-13. https://doi.org/10.1145/3173574.3174205

[19] Arthur D Craig. 2009. How do you feel - now? The anterior insula and human awareness. Nature Reviews Neuroscience 10 (1 2009), 59-70. Issue 1. https //doi.org/10.1038/NRN2555

[20] Shelly L Curran, Michael A Andrykowski, and Jamie L Studts. 1995. Short form of the profile of mood states (POMS-SF): psychometric information. Psychological assessment 7 (1995), 80. Issue 1. https://doi.org/10.1037/1040-3590.7.1.80

[21] Adèle De Jager, Anna Tewson, Bryn Ludlow, and Katherine Boydell. 2016. Embodied ways of storying the self: A systematic review of body-mapping. Forum, qualitative social research 17 (2016), 1-31. Issue 2. https://doi.org/10.17169/fqs17.2.2526

[22] Johan Denollet, Ivan Nykliček, and Ad JJM Vingerhoets. 2008. Introduction Emotions, emotion regulation, and health. Springer, Boston, MA, 3-11. https: //doi.org/10.1007/978-0-387-29986-0_1

[23] Audrey Desjardins and Aubree Ball. 2018. Revealing tensions in autobiographical design in HCI. In Proceedings of the 2018 Designing Interactive Systems Conference (DIS '18). Association for Computing Machinery, New York, NY, USA, 753-764. https://doi.org/10.1145/3196709.3196781

[24] Anselm Doll, Britta K Hölzel, Satja Mulej Bratec, Christine C Boucard, Xiyao Xie, Afra M Wohlschläger, and Christian Sorg. 2016. Mindful attention to breath regulates emotions via increased amygdala-prefrontal cortex connectivity. NeuroImage 134 (2016), 305-313. https://doi.org/10.1016/j.neuroimage.2016.03.041

[25] Liesel Ebersöhn, Ronél Ferreira, Anél van der Walt, and Melanie Moen. 2016. Bodymapping to step into your future: Life design in a context of high risk and high diversity. Juta, Cape Town, South Africa. 228-241 pages.

[26] Maria Fissler, Emilia Winnebeck, Titus Schroeter, Marie Gummersbach, Julia M Huntenburg, Matti Gaertner, and Thorsten Barnhofer. 2016. An Investigation of the Effects of Brief Mindfulness Training on Self-Reported Interoceptive Awareness, the Ability to Decenter, and Their Role in the Reduction of Depressive Symptoms. Mindfulness 7 (6 2016), 1170-1181. Issue 5. https://doi.org/10.1007/s12671-016-0559-z

[27] Jérémy Frey, May Grabli, Ronit Slyper, and Jessica R Cauchard. 2018. Breeze Sharing biofeedback through wearable technologies. In Proceedings of the 2018 CHI Conference on Human Factors in Computing Systems. ACM, New York NY, 1-12. https://doi.org/10.1145/3173574.3174219

[28] Sarah N. Garfinkel, Anil K. Seth, Adam B. Barrett, Keisuke Suzuki, and Hugo D. Critchley. 2015. Knowing your own heart: Distinguishing interoceptive accuracy from interoceptive awareness. Biological Psychology 104 (1 2015), 65-74. https: //doi.org/10.1016/J.BIOPSYCHO.2014.11.004

[29] Eric L Garland, Adam Hanley, Norman A Farb, and Brett Froeliger. 2015. State mindfulness during meditation predicts enhanced cognitive reappraisal. Mindfulness 6 (2015), 234-242. Issue 2. https://doi.org/10.1007/s12671-013-0250-6

[30] Steven M Gillespie, Ian J Mitchell, Dawn Fisher, and Anthony R Beech. 2012 Treating disturbed emotional regulation in sexual offenders: The potential applications of mindful self-regulation and controlled breathing techniques. Aggression and Violent Behavior 17 (2012), 333-343. Issue 4. https://doi.org/10. 1016/j.avb.2012.03.005

[31] Philippe R. Goldin, Kateri McRae, Wiveka Ramel, and James J. Gross. 2008. The Neural Bases of Emotion Regulation: Reappraisal and Suppression of Negative Emotion. Biological Psychiatry 63 (3 2008), 577-586. Issue 6. https://doi.org/10. 1016/J.BIOPSYCH.2007.05.031

[32] Miriam Greenspan. 2004. Healing through the dark emotions: The wisdom of grief, fear, and despair. Shambhala Publications, Boston.

[33] James J Gross. 1998. The Emerging Field of Emotion Regulation: An Integrative Review. Review of General Psychology 2 (9 1998), 271-299. Issue 3. https: //doi.org/10.1037/1089-2680.2.3.271
[34] James J. Gross and Oliver P. John. 2003. Individual Differences in Two Emotion Regulation Processes: Implications for Affect, Relationships, and Well-Being. Journal of Personality and Social Psychology 85 (8 2003), 348-362. Issue 2. https: //doi.org/10.1037/0022-3514.85.2.348

[35] James J. Gross and Robert W. Levenson. 1993. Emotional Suppression: Physiology, Self-Report, and Expressive Behavior. Journal of Personality and Social Psychology 64 (1993), 970-986. Issue 6. https://doi.org/10.1037/0022-3514.64.6.970

[36] J Gruber, A Kogan, J Quoidbach, IB Mauss Emotion, and undefined 2013. 2012. Happiness is best kept stable: positive emotion variability is associated with poorer psychological health. psycnet.apa.org 13 (2012), 1-6. Issue 1. https: //doi.org/10.1037/a0030262

[37] Simeng Gu, Fushun Wang, Nitesh P Patel, James A Bourgeois, and Jason H Huang. 2019. A Model for Basic Emotions Using Observations of Behavior in Drosophila. Frontiers in psychology 10 (2019), 781-781.

[38] G Guest, KM MacQueen, and EE Namey. 2011. Applied thematic analysis. sage publications, United States.

[39] SM Haga, P Kraft, EK Corby Journal of happiness studies, and undefined 2009. 2007. Emotion regulation: Antecedents and well-being outcomes of cognitive reappraisal and expressive suppression in cross-cultural samples. Springer 10 (6 2007), 271-291. Issue 3. https://doi.org/10.1007/s10902-007-9080-3

[40] David Hankerson, Andrea R. Marshall, Jennifer Booker, Houda El Mimouni, Imani Walker, and Jennifer A. Rode. 2016. Does technology have race? dl.acm.org 07-12-May-2016 (5 2016), 473-485. https://doi.org/10.1145/2851581.2892578

[41] Yu Hao, James Budd, Melody Jackson, Mukul Sati, and Sandeep Soni. 2014. A visual feedback design based on a brain-computer interface to assist users regulate their emotional state. In CHI '14 Extended Abstracts on Human Factors in Computing Systems (CHI EA '14). Association for Computing Machinery, New York, NY, USA, 2491-2496.

[42] Yu Hao, Donghai Wang, and James G. Budd. 2015. Design of intelligent emotion feedback to assist users regulate emotions: Framework and principles. In 2015 International Conference on Affective Computing and Intelligent Interaction (ACII). IEEE Computer Society, Los Alamitos, CA, USA, 938-943. https://doi.org/10. 1109/ACII.2015.7344687

[43] Taylor Heffer and Teena Willoughby. 2017. A count of coping strategies: A longitudinal study investigating an alternative method to understanding coping and adjustment. PloS one 12, 10 (2017), e0186057-e0186057. https://doi.org/10. 1371/journal.pone. 0186057

[44] Leah Heiss, Paul Beckett, and Amy Carr-Bottomley. 2016. Redesigning the TransDisciplinary: Working Across Design, Craft and Technological Boundaries to Deliver an Integrated Wearable for Cardiac Monitoring. In Proceedings of the 2016 ACM Conference on Designing Interactive Systems (Brisbane, QLD, Australia) (DIS '16). Association for Computing Machinery, New York, NY, USA, 691-699. https://doi.org/10.1145/2901790.2901794

[45] Yasamin Heshmat, Carman Neustaedter, and Brendan DeBrincat. 2017. The Autobiographical Design and Long Term Usage of an Always-On Video Recording System for the Home. In Proceedings of the 2017 Conference on Designing Interactive Systems (Edinburgh, United Kingdom) (DIS '17). Association for Computing Machinery, New York, NY, USA, 675-687. https://doi.org/10.1145/3064663. 3064759

[46] Oliver Hirsch, MiraLynn Chavanon, Elke Riechmann, and Hanna Christiansen. 2018. Emotional dysregulation is a primary symptom in adult AttentionDeficit/Hyperactivity Disorder (ADHD). Journal of affective disorders 232 (2018), 41-47. https://doi.org/10.1016/j.jad.2018.02.007

[47] Dorothy Howard and Lilly Irani. 2019. Ways of Knowing When Research Subjects Care. Association for Computing Machinery, New York, NY, USA, 1-16. https: //doi.org/10.1145/3290605.3300327

[48] Kristina Höök, Baptiste Caramiaux, Cumhur Erkut, Jodi Forlizzi, Nassrin Hajinejad, Michael Haller, Caroline C.M Hummels, Katherine Isbister, Martin Jonsson, George Khut, Lian Loke, Danielle Lottridge, Patrizia Marti, Edward Melcer, Florian Floyd Müller, Marianne Graves Petersen, Thecla Schiphorst, Elena Márquez Segura, Anna Ståhl, Dag Svanæs, Jakob Tholander, and Helena Tobiasson. 2018. Embracing first-person perspectives in soma-based design. Informatics (Basel) 5, 1 (2018), 8-. https://doi.org/10.3390/informatics5010008

[49] Robert J.K. Jacob, Audrey Girouard, Leanne M. Hirshfield, Michael S. Horn, Orit Shaer, Erin Treacy Solovey, and Jamie Zigelbaum. 2008. Reality-based interaction: a framework for post-WIMP interfaces. In Proceedings of the SIGCHI conference on Human factors in computing systems (CHI '08). Association for Computing Machinery, New York, NY, USA, 201-210. https://doi.org/10.1145/ 1357054.1357089

[50] Anjali Jain. 2015. Digital Jewelry - a 'fashionable' leap in the field of wireless networking. In 2015 2nd International Conference on Computing for Sustainable Global Development (INDIACom). Bharati Vidyapeeth, New Delhi, India, 388392.

[51] Oliver P. John and James J. Gross. 2004. Healthy and unhealthy emotion regulation: Personality processes, individual differences, and life span development. Fournal of Personality 72 (2004), 1301-1334. Issue 6. https: //doi.org/10.1111/J.1467-6494.2004.00298.X 
[52] Lauriann M Jones. 2002. Attachment Object Effects on Children's Anxiety During School-Related Transitions. dissertation. University of North Florida. https: //digitalcommons.unf.edu/etd/230

[53] MF Jung, N Martelaro, PJ Hinds Proceedings of the tenth annual ACM, and undefined 2015. 2015. Using robots to moderate team conflict: the case of repairing violations. dl.acm.org 2015-March (3 2015), 229-236. https://doi.org/ $10.1145 / 2696454.2696460$

[54] Jon Kabat-Zinn. 2009. Wherever you go, there you are: Mindfulness meditation in everyday life. Hachette Books, United states.

[55] Jon Kabat-Zinn. 2012. Mindfulness for beginners: Reclaiming the present moment-and your life. Sounds True, Colorado.

[56] Jon Kabat-Zinn and Thich Nhat Hanh. 2009. . Delta, United States.

[57] Philipp Kanske, Janine Heissler, Sandra Schönfelder, André Bongers, and Michele Wessa. 2011. How to regulate emotion? Neural networks for reappraisal and distraction. Cerebral Cortex 21, 6 (2011), 1379-1388. https://doi.org/10.1093/ cercor/bhq216

[58] Thomas Kosch. 2017. Galvanic Skin Response powered by Arduino. https://thomaskosch.com/index.php/2017/12/17/galvanic-skin-responsepowered-by-arduino/

[59] Nantia Koulidou and Robb Mitchell. 2021. Art Digital Jewellery: Practitioners Perspectives. In Proceedings of the Fifteenth International Conference on Tangible, Embedded, and Embodied Interaction (Salzburg, Austria). Association for Computing Machinery, New York, NY, USA, 1-11. https://doi.org/10.1145/3430524. 3440648

[60] Laura D Kubzansky and Ichiro Kawachi. 2000. Going to the heart of the matter Fournal of Psychosomatic Research 48 (4 2000), 323-337. Issue 4-5. https://doi. org/10.1016/S0022-3999(99)00091-4

[61] Joseph Lampel and Henry Mintzberg. 1996. Customizing customization. Sloan management review 38, 1 (1996), 21-30.

[62] Christopher A. Langston. 1994. Capitalizing on and coping with daily-life events: Expressive responses to positive events. Fournal of Personality and Social Psychology 67 (1994), 1112-1125. Issue 6. https://doi.org/10.1037/00223514.67.6.1112

[63] Richard S. Lazarus. 1984. Stress, appraisal, and coping. Springer Pub. Co., New York.

[64] Tamara Levitt. 2021. Calm [Mobile app]. https://www.calm.com/

[65] Wendy G Lichtenthal and Robert A Neimeyer. 2012. Directed journaling to facilitate meaning-making. Routledge, United Kingdom. 185-188 pages.

[66] Joaquín T Limonero, Joaquín Tomás-Sábado, Jordi Fernández-Castro, M José Gómez-Romero, and Amor Ardilla-Herrero. 2012. Resilient coping strategies and emotional regulation: Predictors of life satisfaction. Behavioral Psychology/Psicologia Conductual 20 (2012), 183-196. Issue 1.

[67] Adam Lobel, Isabela Granic, and Rutger CME Engels. 2014. Stressful Gaming, Interoceptive Awareness, and Emotion Regulation Tendencies: A Novel Approach. Cyberpsychology, Behavior, and Social Networking 17 (4 2014), 222-227. Issue 4. https://doi.org/10.1089/cyber.2013.0296

[68] Andrés Lucero, Audrey Desjardins, Carman Neustaedter, Kristina Höök, Marc Hassenzahl, and Marta E. Cecchinato. 2019. A Sample of One: First-Person Research Methods in HCI. In Companion Publication of the 2019 on Designing Interactive Systems Conference 2019 Companion (San Diego, CA, USA) (DIS '19 Companion). Association for Computing Machinery, New York, NY, USA 385-388. https://doi.org/10.1145/3301019.3319996

[69] Kristina Mah, Lian Loke, and Luke Hespanhol. 2020. Understanding Compassion Cultivation for Design: Towards an Autoethnography of Tonglen. In 32nd Australian Conference on Human-Computer Interaction (OzCHI '20). Association for Computing Machinery, New York, NY, USA, 748-754. https: //doi.org/10.1145/3441000.3441065

[70] Kristina Mah, Lian Loke, and Luke Hespanhol. 2021. Towards a Contemplative Research Framework for Training Self-Observation in HCI: A Study of Compassion Cultivation. ACM Transactions on Computer-Human Interaction (TOCHI) 28, 6 (2021), 1-27.

[71] D Matsumoto, SH Yoo, S Nakagawa Journal of personality, , and undefined 2008 2008. Culture, emotion regulation, and adjustment. psycnet.apa.org 94 (2008), 925-937. Issue 6. https://doi.org/10.1037/0022-3514.94.6.925

[72] Wolf E. Mehling, Cynthia Price, Jennifer J. Daubenmier, Mike Acree, Elizabeth Bartmess, and Anita Stewart. 2012. The Multidimensional Assessment of Interoceptive Awareness (MAIA). PLoS ONE 7 (11 2012), 22 pages. Issue 11 https://doi.org/10.1371/JOURNAL.PONE.0048230

[73] Lisa M Mitchell. 2006. Body and illness: Considering Visayan Filipino children's perspectives within local and global relationships of inequality. Medical Anthropology 25 (2006), 331-373. Issue 4. https://doi.org/10.1080/01459740601025856

[74] Jennifer Murphy, Rebecca Brewer, Caroline Catmur, and Geoffrey Bird. 2017. Interoception and psychopathology: A developmental neuroscience perspective. Developmental Cognitive Neuroscience 23 (2 2017), 45-56. https://doi.org/10. 1016/j.dcn.2016.12.006

[75] Chika Nanayama Tanaka, Hayato Higa, Noriko Ogawa, Minenori Ishido, Tomohiro Nakamura, and Masato Nishiwaki. 2020. Negative Mood States Are Related to the Characteristics of Facial Expression Drawing: A Cross-Sectional
Study. Frontiers in psychology 11 (2020), 576683 - 576683. https://doi.org/10. 3389/fpsyg.2020.576683

[76] Carman Neustaedter and Phoebe Sengers. 2012. Autobiographical Design in HCI Research: Designing and Learning through Use-It-Yourself. In Proceedings of the Designing Interactive Systems Conference (DIS '12). Association for Computing Machinery, New York, New York, USA, 514-523. https: //doi.org/10.1145/2317956.2318034

[77] Donald A Norman. 2013. The design of everyday things (revised and expanded edition. ed.). Basic Books, New York, New York.

[78] D Matsumoto Journal of cross-cultural psychology and undefined 2006. 2006. Are cultural differences in emotion regulation mediated by personality traits? journals.sagepub.com 37 (7 2006), 421-437. Issue 4. https://doi.org/10.1177/ 0022022106288478

[79] Treena Orchard, Tricia Smith, Warren Michelow, Kate Salters, and Bob Hogg. 2014. Imagining Adherence: Body Mapping Research with HIV-Positive Men and Women in Canada. AIDS Research and Human Retroviruses 30 (4 2014), 337-338. Issue 4. https://doi.org/10.1089/aid.2014.0021

[80] Antti Oulasvirta, Esko Kurvinen, and Tomi Kankainen. 2003. Understanding contexts by being there: case studies in bodystorming. Personal and ubiquitous computing 7 (2003), 125-134. Issue 2. https://doi.org/10.1007/s00779-003-0238-7

[81] Michael W Passer and Ronald E Smith. 2004. Psychology: The science of mind and behavior. McGraw-Hill, United States.

[82] Olga Pollatos, Ellen Matthias, and Johannes Keller. 2015. When interoception helps to overcome negative feelings caused by social exclusion. Frontiers in psychology 6 (2015), 786-786. https://doi.org/10.3389/FPSYG.2015.00786/FULL

[83] Peter Pribis. 2016. Effects of Walnut Consumption on Mood in Young Adults, ÄîA Randomized Controlled Trial. Nutrients 2016, Vol. 8, Page 6688 (10 2016), 668. Issue 11. https://doi.org/10.3390/NU8110668

[84] Cynthia J Price and Carole Hooven. 2018. Interoceptive Awareness Skills for Emotion Regulation: Theory and Approach of Mindful Awareness in BodyOriented Therapy (MABT). Frontiers in psychology 9 (2018), 798-798. https: //doi.org/10.3389/FPSYG.2018.00798/FULL

[85] Esti Hayu Purnamaningsih. 2017. Personality and Emotion Regulation Strategies. International fournal of Psychological Research 10 (1 2017), 53-60. Issue 1. https: //doi.org/10.21500/20112084.2040

[86] Nosheen Ramzan and Naumana Amjad. 2017. Cross Cultural Variation in Emotion Regulation: A Systematic Review. Annals of King Edward Medical University 23, 1 (2017), 77-90. https://doi.org/10.21649/akemu.v23i1.1512

[87] Courtney N. Reed and Andrew P. McPherson. 2021. Surface Electromyography for Sensing Performance Intention and Musical Imagery in Vocalists. In Proceedings of the Fifteenth International Conference on Tangible, Embedded, and Embodied Interaction (Salzburg, Austria) (TEI '21). Association for Computing Machinery, New York, NY, USA, Article 22, 11 pages. https: //doi.org/10.1145/3430524.3440641

[88] Abigail Rolston and Elizabeth Lloyd-Richardson. 2017. What is emotion regulation and how do we do it. Cornell Research Program on Self-Injury and Recovery. http://www.selfinjury.bctr.cornell.edu/perch/resources/what-is-emotionregulationsinfo-brief.pdf

[89] Ofir Sadka and Alissa Antle. 2020. Interactive Technologies for Emotionregulation Training: Opportunities and Challenges. In Extended Abstracts of the 2020 CHI Conference on human factors in computing systems (CHI EA '20). ACM, New York, NY, USA, 1-12. https://doi.org/10.1145/3334480.3382894

[90] Bart Santen. 2014. Into the fear-factory: connecting with the traumatic core. Person-Centered and Experiential Psychotherapies 13 (4 2014), 75-93. Issue 2. https://doi.org/10.1080/14779757.2013.871574

[91] Bart Santen. 2015. Treating dissociation in traumatized children with body maps. Guilford Press New York, NY, New York, 126-149.

[92] Corina Sas and Chenyan Zhang. 2010. Do emotions matter in creative design? In Proceedings of the 8th ACM Conference on Designing Interactive Systems (DIS '10). Association for Computing Machinery, New York, NY, USA, 372-375. https: //doi.org/10.1145/1858171.1858241

[93] Thecla Schiphorst. 2011. Self-Evidence: Applying Somatic Connoisseurship to Experience Design. In CHI'11 extended abstracts on human factors in computing systems (CHI EA '11). ACM Press, New York, New York, USA, 145-160. https: //doi.org/10.1145/1979742.1979640

[94] Dennis Schleicher, Peter Jones, and Oksana Kachur. 2010. Bodystorming as embodied designing. Interactions 17 (2010), 47-51. Issue 6. https://doi.org/10. $1145 / 1865245.1865256$

[95] Elena Márquez Segura, Laia Turmo Vidal, and Asreen Rostami. 2016. Bodystorming for movement-based interaction design. Human Technology 12, 2 (2016), 193-251. Issue 2. https://doi.org/10.17011/ht/urn.201611174655

[96] Amanda J Shallcross, Allison S Troy, Matthew Boland, and Iris B Mauss. 2010. Let it be: Accepting negative emotional experiences predicts decreased negative affect and depressive symptoms. Behaviour Research and Therapy 48 (2010), 921-929. Issue 9. https://doi.org/10.1016/j.brat.2010.05.025

[97] Jonathan Silverman. 1997. The aesthetic experience of learning: Sketching new boundaries. The fournal of General Education 46 (1997), 73-95. Issue 2. https://www.jstor.org/stable/27797332 
[98] Will Simm, Maria Angela Ferrario, Adrian Gradinar, Marcia Tavares Smith, Stephen Forshaw, Ian Smith, and Jon Whittle. 2016. Anxiety and Autism Towards Personalized Digital Health. In Proceedings of the 2016 CHI Conference on Human Factors in Computing Systems (San Jose, California, USA) (CHI '16). Association for Computing Machinery, New York, NY, USA, 1270-1281. https://doi.org/10.1145/2858036.2858259

[99] Marie Louise Juul Søndergaard, Ozgun Kilic Afsar, Marianela Ciolfi Felice, Nadia Campo Woytuk, and Madeline Balaam. 2020. Designing with Intimate Materials and Movements: Making" Menarche Bits". Association for Computing Machinery, New York, NY, USA, 587-600. https://doi.org/10.1145/3357236.3395592

[100] Sarah Spence and Christine Courbasson. 2012. The role of emotional dysregulation in concurrent eating disorders and substance use disorders. Eating Behaviors 13 (2012), 382-385. Issue 4. https://doi.org/10.1016/j.eatbeh.2012.05.006

[101] Katta Spiel. 2021. The Bodies of TEI - Investigating Norms and Assumptions in the Design of Embodied Interaction. In Proceedings of the Fifteenth International Conference on Tangible, Embedded, and Embodied Interaction (Salzburg, Austria) (TEI '21). Association for Computing Machinery, New York, NY, USA, Article 32, 19 pages. https://doi.org/10.1145/3430524.3440651

[102] Chloe Taylor, Alexandra Clifford, and Anna Franklin. 2013. Color preferences are not universal. Fournal of Experimental Psychology: General 142, 4 (2013), 1015. https://doi.org/10.1037/a0030273

[103] Muhammad Umair, Miquel Alfaras, Hugo Gamboa, and Corina Sas. 2019. Experiencing Discomfort: Designing for Affect from First-Person Perspective. In Adjunct Proceedings of the 2019 ACM International foint Conference on Pervasive and Ubiquitous Computing and Proceedings of the 2019 ACM International Symposium on Wearable Computers (London, United Kingdom) (UbiComp/ISWC '19 Adjunct). Association for Computing Machinery, New York, NY, USA, 1093-1096. https://doi.org/10.1145/3341162.3354061

[104] Francisco J Varela and Jonathan Shear. 1999. First-person methodologies: What, why, how. Journal of Consciousness studies 6 (1999), 1-14. Issue 2-3.

[105] Jayne Wallace, Kyle Montague, Trevor Duncan, Luís P. Carvalho, Nantia Koulidou, Jamie Mahoney, Kellie Morrissey, Claire Craig, Linnea Iris Groot, Shaun
Lawson, Patrick Olivier, Julie Trueman, and Helen Fisher. 2020. ReFind: Design, Lived Experience and Ongoingness in Bereavement. In Proceedings of the 2020 CHI Conference on Human Factors in Computing Systems (Honolulu, HI, USA) (CHI '20). Association for Computing Machinery, New York, NY, USA, 1-12. https://doi.org/10.1145/3313831.3376531

[106] Wibke Weber. 2019. Towards a Semiotics of Data Visualization - an Inventory of Graphic Resources. In 2019 23rd International Conference Information Visualisation (IV). IEEE Computer Society, Los Alamitos, CA, USA, 323-328. https://doi.org/10.1109/IV.2019.00061

[107] Marcia Stanley Wertz, Marcianna Nosek, Susan McNiesh, and Elizabeth Marlow. 2011. The composite first person narrative: Texture, structure, and meaning in writing phenomenological descriptions. International journal of qualitative studies on health and well-being 6 (2011), 5882. Issue 2. https://doi.org/10.3402/ qhw.v6i2.5882

[108] Clémence Willem, Marie-Charlotte Gandolphe, Méline Roussel, Hélène Verkindt, François Pattou, and Jean-Louis Nandrino. 2019. Difficulties in emotion regulation and deficits in interoceptive awareness in moderate and severe obesity. Eating and Weight Disorders-Studies on Anorexia, Bulimia and Obesity 24 (8 2019), 633-644. Issue 4. https://doi.org/10.1007/S40519-019-00738-0

[109] Donald M Wolfe and David A Kolb. 1984. Career development, personal growth and experiential learning. Organisational Psychology: Readings on Human Behaviour, 4th edn, Englewood Cliffs, Nf: Prentice-Hall 26 (1984), 639 pages.

[110] JungKyoon Yoon, Shuran Li, Yu Hao, and Chajoong Kim. 2019. Towards Emotional Well-Being by Design: 17 Opportunities for Emotion Regulation for User-Centered Healthcare Design. In Proceedings of the 13th EAI International Conference on Pervasive Computing Technologies for Healthcare (Trento, Italy) (PervasiveHealth'19). Association for Computing Machinery, New York, NY, USA, 351-355. https://doi.org/10.1145/3329189.3329227

[111] Wenhai Zhang, Yongqiang Ouyang, Fanggui Tang, Jie Chen, and Hong Li. 2019. Breath-focused mindfulness alters early and late components during emotion regulation. Brain and cognition 135 (2019), 103585. https://doi.org/10.1016/j. bandc. 2019.103585 